\title{
SPORTS PERFORMANCE ANXIETY AND SPORTS CONFIDENCE AMONG COLLEGE ATHLETES: THE MODERATING EFFECT OF FRIENDSHIP QUALITY
}

Gideon I. Juezan ${ }^{1 \mathrm{i}}$, Rodolfo II M. Osorno ${ }^{2}$ 1Sports Director/Instructor 1, Davao del Sur State College, Philippines 2UMDC College Professor, Master Teacher 1, Ramon Magsaysay Central Elem School, Philippines

\begin{abstract}
:
The study endeavored to recognize the moderating effect of friendship quality between sports performance anxiety and sports confidence of varsity athletes in state colleges in Davao del Sur and Davao Occidental. A non-experimental quantitative research design was used, utilizing descriptive, correlational and causative designs and data were taken from $N=119$ college athletes who were asked to respond on questionnaires online. In the analysis of the data, weighted mean, Pearson $r$, mod graph via linear regression were used. Results revealed that sports performance anxiety has a significant relationship with sports confidence and friendship quality significantly related to sports confidence. However, sports performance anxiety does not significantly correlate with friendship quality. Linear regression analysis found out that while sports performance anxiety and friendship quality significantly influence sport confidence among athletes, sports performance anxiety does not significantly influence friendship quality among athletes. Finally, while no moderating effect was noted on friendship quality, regressing it in combination with sports performance anxiety posed a significant influence on the confidence of athletes.
\end{abstract}

Keywords: sports anxiety, friendship, confidence, college student-athletes, moderating effect, Philippines

${ }^{i}$ Correspondence: email gideonjuezan@gmail.com 


\section{Introduction}

Confidence as a quality found in many aspects of society is not anymore, a stranger to the sport. The importance of understanding how confidence varies across time has been encouraged by sport-confidence researchers. Elite athletes have revealed that sports confidence affects their performance through their thoughts, behaviors, and feelings. On the other hand, recent research has shown that success has affected the level of sports confidence and confidence can affect the athlete's success. The world of sport recognizes the importance that sports confidence has on success. But in some cases, sports confidence can be affected when our efficacy expectation is not strong, and our abilities are clearly undeveloped (Gagnon-Dolbec, 2019).

Furthermore, sports confidence is broadly acclaimed by scholars, analysts, and professionals as the foremost basic characteristic affecting sport performances. Sports confidence gives a common system for control and administration of sport self-efficacy. It assists competitors in specified fields related to management and control of sport anxiety, superior execution, and sports accomplishment. In other words, sports confidence could be an overall build-up. Sports confidence can also moderate competitive outrage indications, encourages adapting assets for experiencing sports performance anxiety and causes to support the resumption of control amid the match. Sports confidence before and in the actual game can decide the minimal level of anxiety and with ample time an athlete can decide with much better moves (Craft et al., 2016).

Sports confidence is very important in athletic competition, it is the athlete's quality or state of being strong. But an athlete would not always perform his best due to some thoughts and disturbances, and that is where anxiety in sports strikes in, it always relates to what is sports is (Robinson, 2015). He also stated that anxiety is not always bad for sports confidence but for some instances it helps athletes to boost their alertness in performance. In participating in sports competitions, it is common for an athlete to feel anxious or uneasy with the situation. To add, developmental research appears that positive friendship qualities such as regard upgrade and closeness are related to fulfilling social intuition with peers, positive enthusiastic reactions, higher peer acknowledgement, and versatile motivational and accomplishment forms which result also in good sports confidence (Yavuz, 2019).

There are only a few studies that discussed sports anxiety, sports confidence and friendship quality. The researcher did not come across any similar or existing study using the same variables being conducted at the local or regional setting. Existing studies focus only on the relationship of the main variables which was also outdated while in this study, the researcher will discuss the relationship of each indicator of two identified variables with a moderating effect of another variable. The result of this study may be a good benchmark for a development plan in sports coaching and sports management in the tertiary level in preparation for any upcoming regional and national competition. Therefore, there is a need and urgency to conduct this study to contribute to the existing body of knowledge in the field of physical education and sports. 


\subsection{Review of Related Literature}

This section presents various literature that served as proof and support to all the discussions pertaining to this study of sports performance anxiety, sports confidence, and friendship quality. The independent variable is "the sports performance anxiety with indicators, namely; somatic, worry and concentration disruption" (Smith, Smoll, Cumming \& Grossbard, 2006). The dependent variable is the sports confidence with indicators, namely; "Confidence in physical skills and training, Confidence in cognitive efficiency and Confidence in resilience" (Frischknecht, Pesca \& Cruz, 2016). The moderating variable is "friendship quality with indicators namely, self-esteem enhancement and supportiveness, loyalty, intimacy, things in common, companionship and pleasant play, conflict resolution and conflict." (Scoffier, Maiano \& Loungeville, 2009)

\subsection{Sports Performance Anxiety}

Sports performance anxiety as one of the variables to be discussed in this study will lead this academic work to the indicator of how an athlete and competitor will be affected by anxiety in their sports performance. Related studies about somatic, worry and concentration disruption were gathered as the core apprehension of how sports performance anxiety is associated with this study.

Athletes participating in sports experience different levels of stress from competitive sports (Patel, 2010). For most young athletes (generally 13 to 24 years old, i.e., high-school and college-age group) sports participation is reported to be no more stressful than many other activities of the daily student or work life in general where competition is involved, and performance is measured.

Moreover, it was speculated that in the field of sports, an athlete would not always perform its best due to some thoughts and disturbances, and that is where anxiety in sports strikes in, it always relates to what is sports is (Robinson, 2015). He also stated that anxiety is not always bad for an athlete but for some instances it helps athletes to boost their alertness in performance. Participating in sports competitions is common for an athlete to feel anxious or unease with the situation. As for the sports field where anxiety is concerned, it is said that anxiety in sporting events is common and is its environment which can be difficult also in a team relationship.

Somatic as the first indicator of sports performance anxiety will tell us the information of various physical anxieties like problems in athletic training and physical preparation.

Meanwhile, it was stated that athletes are more likely influenced by various psychological factors, the performance level and outcome in competitive sports really matter on physical attributes and somatic strategies (Radochoński, 2019). For many sports, it has been the concern of various studies on how to handle the linkages of anxiety and level of performance. If athletes do not have enough physical skills and background to manage discouragement in a game, they will be left unprotected to risks of badly off performance, lack of success, and even vital tear in muscle or injury. 
With this, examination additionally shows that significant levels of serious somatic anxiety increase injury weakness in certain competitors (Williams and Scherzer, 2006). Also, Smith, Ptacek, and Patterson (2000) found that while encountering life stress, competitors who were higher in execution tension were at fundamentally more danger for injury compared to those with low degrees of anxiety in execution.

Worry, as the second indicator of sports performance anxiety, will tell us the information of the various related studies about sports performance and emotional anxieties encountered before and in the actual game.

To further, it was being speculated that anxiety, as the customary negative emotion dealt by worry, influences perceptions in sporting events and competitions, where many athletes consider anxiety to weakens players towards performance, which in result shrink the performance of athletes (Weinberg RS., 2011).

In addition, sports performance anxiety happens when the central focus of the person is the anxiety itself. Giving more importance to this feeling than the performance or results of the sports activity, "It stems from a tendency to resist and fight your anxiety, rather than to accept and work. Moreover, mistakes are appeared as a natural part of the learning manner, no longer as something to be dreaded and averted due to worry of punishment from the teach. In such surroundings, athletes need to be less probably to experience threat concerning their capability to outperform others and therefore revel in less anxiety" (McArdle \& Duda, 2014).

Concentration disruption, as the last indicator of sports performance anxiety, will tell us the information and various related studies about cognitive and concentration disruption. Psychological factors and anxieties affect the athlete's performance in focusing on the game.

To start, Angulo (2013) highlighted the anxiety of social phobia. In sports, if the concentration is disrupted it directly affects the physical performance of the athlete. In the sporting field, the person affected is an athlete and the action to perform is a sport activity. The audience is the crowd, sports fans and coaches and other team members. Stage fright might transform the feeling into a motivational technique, or they can respond negatively. An athlete can perceive a tournament, game, or even a moment by the player as two opposite situations: threat or challenge.

Anent to this, it was speculated that generally, athletes are apprehensive for many and various causes, such as the success of sporting and its importance, or the distinction between athletes' skills and abilities necessitate for their sport, and these aspects can have a defeatist effect on their performance (Sedarati, 2007). Academic work shows that change of state and excitement, or disrupted feeling can change and affect the performance of the athlete.

Sports performance anxiety is no anymore, a stranger in the field of sports. There are a lot of factors to consider if we want to prepare our athletes in a game. Based on the related literature gathered above, athletes participating in sports experience different levels of stress from competitive sports (Patel, 2010). This anxiety may be in form of somatic, worry or concentration disruption (Smith, Smoll, Cumming \& Grossbard, 2006). 


\subsection{Sports Confidence}

Sport confidence is regarded as a key success factor for athletes at all levels. According to studies, sport-confidence is a multifaceted concept rather than a latent variable construct, and the sport-confidence model established three distinct forms of sport-confidence (i.e., physical skills and training, cognitive efficiency, and resilience) that are needed for sporting success (Machida, 2017).

Apart from this, sport-confidence regarding physical skills and training (SC-Physical Skills and Training) is the first category of sport-confidence, and it pertains to athletes' confidence in their training and abilities to function the physical skills required to be successful in sport (Vealey \& Chase, 2008).

Besides, multiple factors such as an athlete's playing position (Michael, 2011), injury (Magyer \& Feltz, 2003), age (Wilson et al., 2004), and innate factors have been identified to influence sources of sport-confidence (Hays et al., 2007)

As mentioned by Chandel (2018), having a program of training helps an athlete to enhance his performance in competition. The maturity level of trusting the ability will be far beyond the normal state of an athlete, described as sports-confidence which relies on the assumption or level of conviction an athlete has about their ability to succeed in sports.

The second category of sport-confidence is sport-confidence towards cognitive efficiency (SC-Cognitive Efficiency), which is characterized as athletes' eagerness to sustain maximum focus and concentration while making critical decisions required for effective results (Vealey \& Chase, 2008).

Subsequently, sources of sport-confidence influence subsequent levels of sportconfidence, which then directly impacts athletes' affect (e.g., satisfaction, enjoyment), behavior (e.g., effort, performance), and cognition (cognitive state anxiety, SC-state) (Vealey, 1998).

Undoubtedly, the power to regulate one's mental and emotional behaviors helps task execution while also laying a psychological foundation for trust and well-being (Boyd \& Zenong, 2018). When a person feels like they have some control over their psycho-somatic function, it motivates them to keep trying to improve it (Wuff \& Toole, 2017).

Finally, sport-confidence about resilience (SC Resilience) is described as an athlete's belief in their capacity to reorient and recover from performance missteps, as well as resolve adversity and setbacks, to achieve success in sport (Vealey \& Chase, 2008).

Self-confidence as is of the foremost imperative factors related to sports execution increase the capacity to manage emotion and gives plausibility for a competitor to control negative feelings more viably. In addition, research showed that in competitors, above levels of sports confidence are observed with valuable capacity (Martens et al., 2007).

The impact of sport-confidence on control and diminishing negative feelings have been affirmed in totally different ponders (Lombardo et al., 2018). Based on this, one plausibility is that sport-confidence makes a difference competitor to control and diminish negative feelings particular to athletic competition like sports anxiety. This 
capability strengthens the athlete's sense of dominance and justification amid the game and progresses his/her sports execution.

\subsection{Friendship Quality}

In psychosocial literature (Rubin, Bukowski, 2019) stated that peer perceptions of children and adolescents have been examined on three levels of social complexity: interactions, relationships, and classes. Interactions are the simplest degree of complexity and apply to a short-term social exchange between two people. Then there are relationships, which add a layer of complexity to young people's interactions with their peers by considering the meanings, desires, and emotions that arise from multiple interactions between people (Rubin et al., 2017).

Proof of this, it was stated that for an individual to find and make new friends there must be socialization and time which can be done through playing sports (Humara, 2018). Playing against one another as friends, respecting races and abilities, talking about experiences and time for a good talk, are some of the best things we can get through sporting and playing.

\section{A. Self-esteem Enhancement and Supportiveness}

In addition to this, the connection and involvement an athlete experiences in playing sports can open onto various development (Cox, 2017), For example, individual athlete boosts up their self-esteem whenever they feel believed by their teammates, more happiness in activities and want to participate whenever there is an activity.

To add, developmental research appears that positive friendship qualities such as regard upgrade and closeness are related to fulfilling social intuition with peers, positive enthusiastic reactions, higher peer acknowledgement, and versatile motivational and accomplishment forms (Ladd, 2019).

\section{B. Conflict Resolution}

In addition to this, it was being pronounced that a game experience of athletes can make the teamwork wonderful and can enhance the concern with the principles of right and wrong behavior of a matured workgroup (Englert \& Bertrams, 2012). You learn a lot and continue absorbing knowledge and wisdom whenever you are part of them and feel a state of belongingness to a particular group.

In like manner, Weiss and Smith (2016) have recognized that measurements of friendship quality may have vital suggestions for motivation related result factors within the setting of sport. Utilizing the SFQS, they distinguished youngsters' discernments of "ability to resolve conflict" and "companionship" with a designated best companion in tennis to be emphatically related with commitment and delight of the sport.

\section{Things in Common}

Moreover, detailed negative friendship measurements included encounters of strife, selling out, and detachment. In an advance investigation, Weiss and Smith (2016) 
amplified prior work (Weiss et al., 2018) and conceptualized six major measurements of companionship quality in youth sport. Particularly, companionship, enthusiastic bolster, devotion, closeness, things in common, strife determination, and encounters of strife reflected the overwhelming measurements by which youth sport companionship quality was recommended to be judged.

To add, inside the peer bunch, close friends in specific offer assistance upgrade self-esteem, buffer depression and stretch, and fulfill needs for companionship, closeness, and passionate bolster (Hartup, 2019).

\section{Intimacy}

In addition, research in formative settings has distinguished positive measurements of children's friendship quality to be related with a variety of important result factors such as expanded fulfillment with peer relations, positive relevant passionate reactions, peer acknowledgement, improved inspiration, and improved accomplishment (Ladd, 2019).

Furthermore, Bartholomew (2017) has recommended that two people who are shakily connected and thus more likely to hold negative working models of themselves and others within the setting of connections, will have more noteworthy issues with closeness and the arrangement of near bonds within the peer bunch than will more safely connected people.

\section{E. Conflict}

Besides, negative measurements of friendship quality have been connected to maladaptive results such as negative demeanors, peer dismissal, and behavioral challenges (Coie \& Cillessen, 2019).

\section{F. Companionship and Pleasant Play}

Accordingly, Ullrich-French and Smith (2017) have too distinguished that recognitions of positive measurements of friendship quality from the SFQS were emphatically related to satisfaction and levels of self-determined inspiration in youth soccer.

Also, Smith (2018) has proposed that research into youth sport companionships can be inspected on distinctive levels of social complexity. To date, research consolidating the SFQS has tended to center on individuals' reports of the friendship qualities they encounter with an assigned "best friend," subsequently paying specific consideration to a single, dyadic relationship.

\section{G. Loyalty}

For case, Cohn (2019) has proposed that unreliable children may be "primed" to expect dismissal and maybe speedy to depend on unfriendly interaction styles, eventually restricting their capacity to induce at the side others on a more "general" level. 


\subsection{Correlation between Variables}

This subsection presents the relationship of the factors to clarify the relationship and significance of its linkages. Though, anxiety has regularly been cited as having a critical part in sports. Martens, Burton (2019) recommended that cognitive anxiety (stress) is contrarily related to sports confidence. In this way, characteristic sport-confidence and competitive introductions impact state sport-confidence and self-efficacy; cognitive anxiety is conversely related to both state sport-confidence and self-efficacy. At last, inquire about and recounted prove have recommended that both self-confidence and anxiety impact execution. Self-confidence upgrades execution through cognitive anxiety disables it (Feltz, 2018)

In addition, recounted evidence and the media have recommended that numerous competitors are engrossed with the result of competitive occasions. In spite of the fact that a crave to win can, at times, coordinate behavior, it can moreover have negative results (Orlick, 2017). In specific, low self-confidence, tall anxiety, and, eventually, destitute exhibitions are frequently famous in competitors who hold unreasonable result objectives. In contrast, competitors who are more concerned with performing well in their sport show up more self-confident and less on edge and may perform closer to their potential (Martens, 2017).

Apart from this, Martin (2016) speculated result objectives can diminish inspiration and exertion in two ways. In case competitors are considerably less skewed, competitors may not attempt their best but may attempt fair difficult enough to win. In contrast, when the competition is predominant, competitors know that winning is impossible, and they may not put forward their best endeavors. A competitor holding a reasonable execution objective, on the other hand, can select a fittingly challenging standard. In brief, execution objectives give measures that can upgrade sport-confidence while result objectives can weaken sport-confidence.

Fair as a competitive introduction can influence state sport-confidence, Vealey (1986) has shown that an individual's disposition toward being self-confident in sport, or characteristic sport-confidence, too impacts state sport-confidence. As a result, both characteristic wear certainty and competitive orientations may impact state sport certainty. For illustration, Vealey (1988) found that competitors high in characteristic sport-confidence who held a performance introduction were also high in state wear certainty. Competitors who have high state sport-confidence levels do so since these quick, precompetitive sentiments are based on controllable, adaptable, and practical execution objectives that an execution introduction gives. Competitive introductions and characteristic sport-confidence may impact self-efficacy, which may be a particular frame of state sport-confidence, but inquire about analyzing the relationship between competitive introductions and self-efficacy is missing.

It should be noted, numerous analysts (Sonstroem and Bernardo, 2018) have fought that interindividual estimations are improper when analyzing the connections between anxiety and performance, as such estimations are not touchy to person contrasts in anxiety or performance. As intra-individual estimations of anxiety, self-confidence and 
execution control for such contrasts, we hypothesized that the connections between cognitive anxiety and execution and between self-confidence and execution would be more grounded when these builds were measured intra-individually instead of interindividually.

Conversely, studies particularly analyzing friendship quality show that poorer fellowship quality increments the risk of various undesirable conditions (Giles, Glonek, Luszcz, \& Andrews, 2019). Conceivably, at that point, an imperative angle of the burden of SAD is its impact on companionships. Shockingly, small is known approximately whether SAD, or indeed higher social anxiety, causes disability in grown-up friendships. Particularly, in a ponder that inspected not only social anxiety and peer victimization, but moreover friendship negativity, friendship bolster, and peer acknowledgment, Tillfors, Persson, Wille'n, and Burk (2018) found that only peer acknowledgment tentatively anticipated social anxiety, while social anxiety tentatively anticipated relationship back for boys (but not girls) and peer victimization for young ladies (but not for boys). Taken together, these ponder propose that viewpoints of peer connections may proportionally anticipate social anxiety over time. In spite of the fact that it is conceivable that these impacts seem to work in a comparable way all through adulthood, we are not mindful of any longitudinal ponders of this sort focusing on grown-ups.

Founded by the above literature, the variables of the study are sports performance anxiety and sports confidence. The moderating variable is athlete friendship quality. The findings, readings and relevant studies are valuable to the study. The dependent variable is sports performance anxiety with its indicators; somatic, worry and concentration disruption. The independent variable is sports confidence includes confidence in physical skill and training, confidence in cognitive efficiency and confidence in resilience. These readings are valuable in determining the relationship between sports performance anxiety and sports confidence and the moderating effect of athlete friendship quality of college student-athletes of state colleges and universities. This will moreover serve as a reinforcement to the presentation, results, and discoveries of the study.

\subsection{Theoretical Framework}

The sports confidence concept is derived from the self-efficacy conceptual model. Selfefficacy beliefs are characterized as an individual's perceptions of their own abilities in particular circumstances (Bandura, 1977). Self-efficacy theory has been applied to describe actions in a variety of psychological fields, and it is the theoretical foundation for many sport confidence-oriented performance research studies (Vealey, 1986; Weinberg \& Gould, 2011).

Within this theory, self-efficacy is described as a specific kind of expectancy belief. As a product of a complex process of self-persuasion, self-efficacy relies on cognitive processing of diverse sources of efficacy information including mastery experiences (e.g., past performance), vicarious experiences (e.g., modeling), verbal persuasion (e.g., pep talk), and somatic and emotional states (e.g., anxiety; Bandura, 1997). In essence, individuals who feel efficacious are more likely to perform at a higher level, try new 
behaviors, expend more effort on those behaviors, and persevere longer when they encounter challenges. To date, many studies have suggested that self-efficacy is a major determinant of activity choice, willingness to expend effort, performance, and persistence in sport and physical education (Feltz \& Mugno, 1983) In particular, higher self-efficacy would lead to greater persistence and better performance than lower self-efficacy.

This study is additionally secured on the attachment theory (Bowlby, 1973) expressed that in sport and exercise psychology, attachment theory has recently been utilized to understand (how competitors and coaches see and adapt with fears and tensions, wounds, and execution droops; and (b) how individual connections (parentathlete or parent-child) and social connections (coach-athlete, athlete-athlete) offer assistance their individuals to either prosper or decrease. The offer of attachment theory to clarify an entire host of investigating questions has started investigating inside sport and exercise psychology that has the potential to progress hypothesis, estimation, and hone.

This study moreover bolstered by the social cognitive hypothesis Bandura (1986), which express the potential to have a significant impact on coaching, competitors, and sport programs. By taking a social-cognitive approach to coaching, coaches can offer assistance to their competitors through the forms of perception, impersonation and support of worthy social behaviors, learning behaviors, motor behaviors and champion behaviors. The realization that competitors are scrutinizing everything that coaches do can be very overwhelming. However, it can also be energizing and thought-provoking to think that a coach has the capacity to educate, impact and rouse competitors essentially by having them watch his or her behavior and the behaviors of others who are a necessary part of the program. Coaches have the potential to create a contrast within the lives of their competitors on an everyday premise, and by grasping the thoughts and applying the concepts related to the social cognitive hypothesis, coaches will be well on the way to moving forward the athletic involvement for all competitors, on and off the field.

\subsection{Conceptual Framework}

The dependent variable of this study is sports performance anxiety taken from Measurement of Multidimensional Sport Performance Anxiety in Children and Adults: The Sport Anxiety Scale-2 with the indicator by (Smith, et. Al, 2006) with the indicators somatic, worry and concentration disruption.

The independent variable of this study is sports confidence taken from Adaptation and Validation of Sport-Confidence Measure to Gymnasts and Football Players by (Frischknecht et al. 2016) with the indicators; physical skills and training, cognitive efficiency, and resilience.

The moderating variable of this study is friendship quality taken from Factor Validity and Reliability of the Sport Friendship Quality Scale in a French adolescent sample by (Scoffier-Mériaux, et. al, 2009) with the indicators; Self-esteem Enhancement and supportiveness, loyalty, intimacy, things in common, conflict resolution and conflict. 
The inter-connection of variables is shown in the conceptual framework presented in Figure 1. In this framework we will go to find the impact of the Independent Variable: sports performance anxiety to the dependent variable: sports confidence with the presence of the moderation variable: friendship quality.

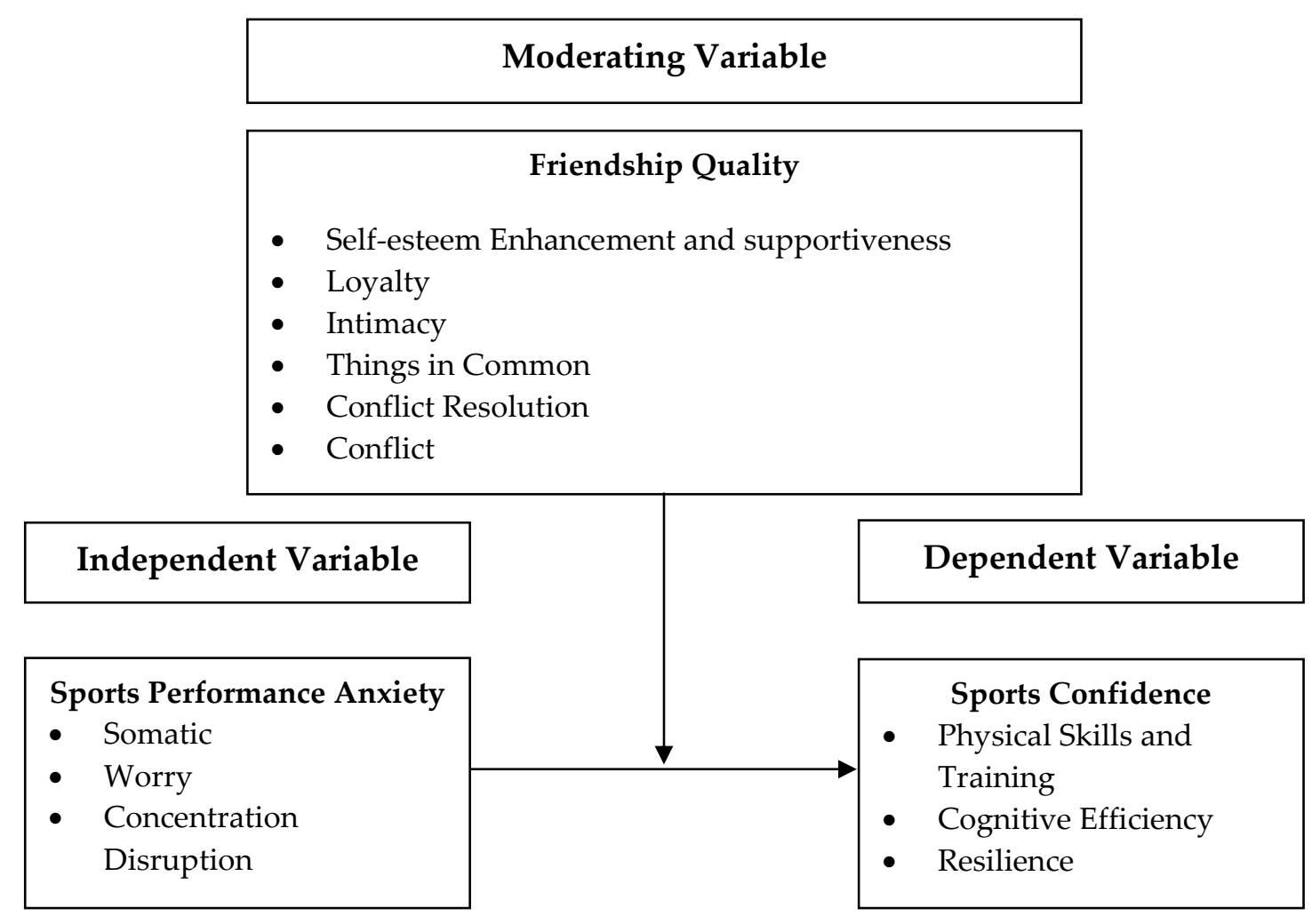

Figure 1: Conceptual Framework showing the variables of the study

\subsection{Significance of the Study}

The result of the study will be useful to the field of instruction and sports as this study will bargain with sports performance anxiety and sports confidence of student-athletes which is imperative within the sports world. The school pioneers will also take advantage of this study in terms of giving data on the result of how friendship quality influences sport performance anxiety and sports confidence. Colleges are organizations that moreover require a thorough examination, particularly on their regulations and parts in supporting and giving for student-athlete needs. Competitor execution in terms of the factors is a vital figure in state colleges to be surveyed and reflected by the college organization, instructors, and pioneers. College directors and sports facilitators will be given actualities on sports performance anxiety and sports confidence.

These variables can be valuable in spurring the coaches, Physical education instructors and fitness teachers in giving their best and bringing them to the programs and exercises for student-athletes and sports competitors with possibilities to gotten to be professional players. For PE instructors, this academic work may serve as a focal point on the implication of sports performance anxiety to sports confidence and the significance 
of friendship quality. Sports facilitators are crucial in giving student-athletes all the assistance that they require. As college educators, coaches, and sports facilitators, they are not as they were instructors but to the moment guardians to student-athletes. Sport exploration and exposure with this variable could be an instrument to extend the intrigued of student-athletes in sports and unfold their potential as competitors. As part of the school community, sports performance anxiety, sports confidence and friendship quality are crucial. For student-athletes, the quality of education empowers them to attain more as they are beneficiaries of well supported and professionally trained teachers. This study can be utilized as the premise for future analysts to form follow-up research on the subject under examination.

\subsection{Definition of Terms}

The preceding fundamental terms utilized in this study are characterized conceptually and operationally for a better understanding of ideas:

Sports Performance Anxiety: in this study, this refers to the anxiety felt by the athlete and competitors in practice and the actual game.

Sports Confidence: in this study, this refers to having a self-assured perception which is your belief in your ability to complete a physical skill or task required in your sport.

Friendship quality: In this study, this refers to self-esteem enhancement and supportiveness, loyalty, intimacy, things in common, conflict resolution and conflict of the athlete.

DSSC: Davao del Sur State College.

SPAMAST: Southern Philippines Marine and Aquatic School of Technology.

\section{Method}

This chapter deals with the different methods of the study including research design, research locale, population and sample, research instruments, data collection, statistical tools, and ethical consideration.

\subsection{Research Design}

This study employed a non-experimental quantitative design. Specifically, this study applied a correlational research approach since the study seeks to establish the relationship between sports performance anxiety, sports confidence and friendship quality among student-athletes of DSSC and SPAMAST. The researcher will use a stratified sampling design in identifying the sampling size of the respondents with the Yamane formula.

\subsection{Research Locale}

The study will be conducted in the State Colleges of Davao Occidental and Davao del Sur. Compromising two colleges namely, Davao del Sur State College located in the City of Digos Province of Davao del Sur, SPAMAST located in the province of Malita, Davao 
Occidental. The researcher pinpoints these colleges as the locale of the study considering that these two colleges are identified as one school college split into two. With this, the two colleges were considered as new in conducting sports development which needs data for the improvement of the athletes and the sports program.

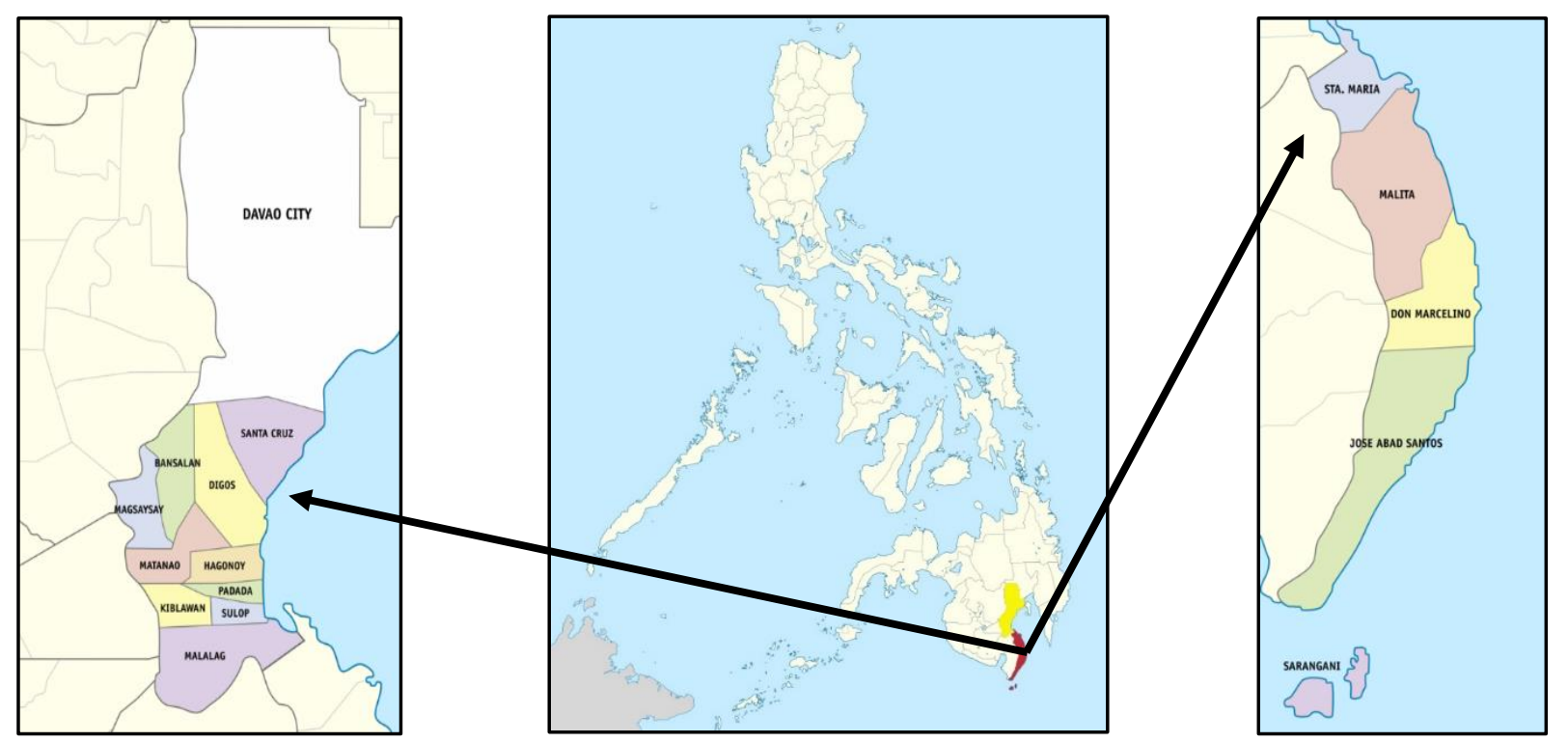

Figure 2: Maps of the Philippines, Davao del Sur and Davao Occidental

As shown in Figure 2, Region XI is located on the southeastern portion of Mindanao, and consists of five provinces, namely: Compostela Valley, Davao del Norte, Davao del Sur, Davao Oriental, and Davao Occidental. Davao del Sur is a province in the Philippines located in the Davao Region in Mindanao. Its capital is Digos City. The province is bounded by Davao del Norte to the north, Davao Occidental to the southeast, North Cotabato and Sultan Kudarat to the west, South Cotabato and Sarangani to the south-west, and the Davao Gulf to the east. Davao Occidental is the 81st and newest province in the Philippines located in the Davao Region in Mindanao. Its capital is the municipality of Malita. To the east lies the Davao Gulf.

\subsection{Population and Sample}

There will be a total of 119 student-athletes (team sports) from the two state colleges under the Province of Davao del Sur and Davao Occidental, specifically the following Colleges: DSSC and SPAMAST. Stratified random sampling will be employed in the study such that all college Student-athlete will have a chance to be selected and considered for inclusion in the final sample. The distribution is as follows: 63 respondents for DSSC and 56 respondents for SPAMAST. With the master list of all student-athletes under the two state colleges which will be secured from the sports office in each college, 30 respondents will be randomly selected each using bowl where all the names of the student-athletes will be placed. In this method, there is a possibility that each student in 
the sample of population could be selected as a subject. This is to ensure that the results will be comprehensive to the context currently studied.

Further, only student-athletes are included as samples as they are the only ones who fit to the criteria that could answer the questions in the survey questionnaire of the study. Other student-athletes who are not enrolled in the state college and who do not belong to the identified areas are deemed excluded from the study. Lastly, studentathletes with the individual event will be excluded in the study including those who do not belong to the identified areas are also deemed excluded from the study. The respondents will be chosen accordingly to answer the questionnaire with confidentiality. The target respondents are free to decline from participating the survey. They are never forced to answer the research questionnaire and encouraged to return the same to the researcher for its automatic disposal.

\subsection{Research Instrument}

There are three sets of surveys which can be adapted from distinctive authors and will be approved by experts on survey development. The adjusted standardized survey is substantial in contents for they are already tested and demonstrated by the author because it will undergo modification to classify the questions. The survey is planned in a really comprehensive frame with the assistance of the expert validators to supply the respondents with ease and comfort in replying each question and in understanding the objective of the academic work.

The researchers adopted existing scales in making the three-part survey instrument. Survey will be established and answered through a Google form. The link will be shared online to groups of athletes and pages of each school. The first part is the Measurement of Multidimensional Sport Performance Anxiety in Children and Adults: The Sport Anxiety Scale-2, Smith, Smoll, Cumming and Grossbard (2006), which consists of three indicators: somatic, worry, concentration and disruption. The second part is the Adaptation and Validation of Sport-Confidence Measure to Gymnasts and Football Players, Frischknecht, Pesca, and Cruz (2016) to measure the confidence level of athletes. The scale consists of three indicators: confidence in physical skills and training, confidence in cognitive efficiency and confidence in resilience. The last part is the Factor Validity and Reliability of the Sport Friendship Quality Scale in a French adolescent sample, Scoffier, Maiano and Longueville (2009) to measure the friendship quality of the athletes. The scale consists of six indicators: Self-esteem Enhancement and supportiveness, Loyalty, Things in Common, Companionship and Pleasant Play, Conflict Resolution and Conflict.

The variables will be measured on a five-point Likert-type scale of 1 to 5, anchored with "never manifested" to "always manifested." The ranges for the means of the athletic mental energy survey questionnaire and the corresponding verbal descriptions are presented in the table below. 
Table 1: For the Sports Performance Anxiety, Systems

with their Respective Range of Means and Descriptions are as Follows

\begin{tabular}{|c|c|c|c|}
\hline $\begin{array}{c}\text { Range of } \\
\text { Means }\end{array}$ & $\begin{array}{c}\text { Numerical } \\
\text { Value }\end{array}$ & $\begin{array}{c}\text { Verbal } \\
\text { Description }\end{array}$ & Interpretation \\
\hline $4.20-5.00$ & 5 & very high & $\begin{array}{c}\text { This means that the level of sports performance } \\
\text { anxiety is always manifested. }\end{array}$ \\
\hline $3.50-4.49$ & 4 & high & $\begin{array}{c}\text { This means that the level of sports performance } \\
\text { anxiety is oftentimes manifested. }\end{array}$ \\
\hline $2.50-3.49$ & 3 & moderate & $\begin{array}{c}\text { This means that the level of sports performance } \\
\text { anxiety is sometimes manifested. }\end{array}$ \\
\hline $1.50-2.59$ & 2 & low & $\begin{array}{c}\text { This means that the level of sports performance } \\
\text { anxiety is seldom manifested. }\end{array}$ \\
\hline $1.00-1.49$ & 1 & very low & $\begin{array}{r}\text { This means that the level of sports performance } \\
\text { anxiety is never manifested. }\end{array}$ \\
\hline
\end{tabular}

Table 2: For the Sports Confidence, Systems with their Respective Range of Means and Descriptions are as Follows

\begin{tabular}{|c|c|c|c|}
\hline $\begin{array}{c}\text { Range of } \\
\text { Means }\end{array}$ & Numerical Value & $\begin{array}{c}\text { Verbal } \\
\text { Description }\end{array}$ & Interpretation \\
\hline $4.20-5.00$ & 5 & very high & $\begin{array}{c}\text { This means that the respondent always practiced } \\
\text { the item related to sports confidence. }\end{array}$ \\
\hline $3.40-4.19$ & 4 & moderate & $\begin{array}{c}\text { This means that the respondent oftentimes practiced } \\
\text { the item related to sports confidence. }\end{array}$ \\
\hline $2.60-3.39$ & 3 & low & $\begin{array}{c}\text { This means that the respondent seldom practiced } \\
\text { the item related to sports confidence. } \\
\text { the item related to sports confidence. }\end{array}$ \\
\hline $1.80-2.59$ & 2 & very low & $\begin{array}{c}\text { This means that the respondent never practiced } \\
\text { the item related to sports confidence. }\end{array}$ \\
\hline $1.00-1.79$ & 1 & \multicolumn{2}{|c}{} \\
\hline
\end{tabular}

Table 3: In evaluating the level of friendship quality, the following scale will be used

\begin{tabular}{|c|c|c|c|}
\hline $\begin{array}{c}\text { Range of } \\
\text { Means }\end{array}$ & $\begin{array}{c}\text { Numerical } \\
\text { Value }\end{array}$ & $\begin{array}{c}\text { Verbal } \\
\text { Description }\end{array}$ & Interpretation \\
\hline $4.20-5.00$ & 5 & very high & $\begin{array}{c}\text { This means that the respondent always } \\
\text { manifested the item related to athlete friendship } \\
\text { quality. }\end{array}$ \\
\hline $3.40-4.19$ & 4 & high & $\begin{array}{c}\text { This means that the respondent oftentimes } \\
\text { manifested the item related to athlete friendship } \\
\text { quality. }\end{array}$ \\
\hline $2.60-3.39$ & 3 & moderate & $\begin{array}{c}\text { This means that the respondent sometimes } \\
\text { manifested the item related to athlete friendship } \\
\text { quality. }\end{array}$ \\
\hline $1.80-2.59$ & 2 & low & $\begin{array}{c}\text { This means that the respondent seldom } \\
\text { manifested the item related to athlete friendship } \\
\text { quality. }\end{array}$ \\
\hline $1.00-1.79$ & 1 & low & $\begin{array}{c}\text { This means that the respondent never manifested } \\
\text { the item related to athlete friendship quality. }\end{array}$ \\
\hline
\end{tabular}




\subsection{Data Collection}

The information will be accumulated in a precise strategy. Firstly, earlier the conduct of the study, the researcher will send a letter inquiring authorization from the College Presidents. Following, the researcher will address the letter of authorization to the College Presidents of DSSC and SPAMAST. A pilot testing will be conducted among student-athletes in private colleges in Davao del Sur with thirty respondents. Upon endorsement, overview surveys will be managed to the student-athletes of the two SUCs in the Davao Region.

With the approval of the sports coordinator of each school, the researcher will forward the link to every available group chat and group page of the school. Before the administration of the questionnaires, the study will be introduced by the researcher to the respondents and the research tool and its purpose will be explained to them. Then, the researcher will orient the respondents about the appropriate manner of accomplishing the questionnaires and will be explained to them all the items individually and thoroughly to ensure valid and reliable results.

\subsection{Statistical Tools}

For more comprehensive translation and examination of the information, the following measurable instruments will be utilized.

Mean and standard deviation: this will be used to describe the levels and variability of sports performance anxiety, sports confidence and friendship quality of athletes.

Pearson product-moment correlation: this test was used to determine the significance of the relationship between sports performance anxiety and sports confidence, sports performance anxiety and friendship quality and friendship quality and sports confidence of athletes.

Tests of moderating effect: this will be used to determine the moderating effect of sport friendship quality between sport performance anxiety and sport confidence among college athletes. Hierarchical linear regression analysis is used to check the amount of change of the variance in every step, while mod graph displays the summary of means of the interactions.

\subsection{Ethical Considerations}

The researcher will watch full moral guidelines within the conduct of the academic work taken after the study convention assessments and standardized criteria, especially in overseeing the populace and information as, but not restricted to:

Voluntary participation. All student-athletes who will be included within the academic work will be given the free will to take an interest without any frame of result or punishment. Subsequently, the reason and the benefits of the ponder will be displayed to the respondents, the rights of the respondents to contribute to the study will be carefully considered and followed upon. 
Privacy and confidentiality. The researcher will collaborate with the respondents with awesome care to ensure their nobility and their scholarly status. The analyst will clarify to the respondents that their personalities will be managed with most extreme privacy.

Informed consent process. The researcher will completely educate the respondents of the study, the basis of the ponder and a depiction of the strategies that will be utilized within the conduct of the research. Subsequently, the researcher will empower criticism from the respondents with respect to additional enquiries as to the objective of the study, the research surveys, and the strategies of conducting academic work. Also, the researcher will advise the respondents how the result of the study will be utilized. To this conclusion, the researcher will guarantee the respondents that the result of the groundwork will be utilized exclusively for the aiming reason of the academic work.

Recruitment. The recruitment of the members will be based on consideration criteria where he/she is fit with the measures set by the researcher. No individual will answer the questionnaire if he/she does not qualify the criteria. They will be informed through a letter addressed to the department heads and supervisors.

Risks. The study will not involve in high risks of situations that the respondents may experience. Mitigating measures will be also considered, to include the psychological, financial, and physical preparations. This study has no risk in the conduct since the respondents are student-athlete and this shall be conducted in accordance with due process.

Benefits. The researcher will prompt the student-athletes on the benefits and the dangers that interest within the study involves. The researcher will boost the focal points that the student-athletes as respondents would gain from partaking within the study and guarantee that the drawbacks would be reduced.

Biosafety. The study will not bargain with medical or logical experimentations that jeopardized biological and natural subjects.

Plagiarism. The researcher will utilize the turn-it-in software to secure that there will be no strand and piece of deception from past considers on the principles of this ponder. This is also to acknowledge the dependence on another person's ideas or words, and to distinguish own work clearly from the sources.

Fabrication. In the same way, creation will be maintained a strategic distance from by the researcher wherein no trace/evidence of purposefulness deception of what has been done. No manufacture of information and/or comes about, or deliberately putting forward wrong conclusions. No irregularity with the existing writing among the data will be included in the composition.

Falsification. This will also be taken into thought in which no trace of intentionally distorting the work to utilize a demonstrate or hypothetical introduction. No proof of claiming or embellishments.

Conflict of Interest (COI). There will be a set of conditions in which a proficient judgment concerning essential intrigued such as the participants' welfare or the 
legitimacy of the investigate tends to be impacted by an auxiliary intrigued such as money related or scholarly gains or acknowledgement.

Deceit. In this study, there is no deceit. Everything written and reflected is true and has undergone validation and thorough checking from different experts in the field of research. This will be maintained a strategic distance in which evidence that the advantage of deluding the respondents exceed any conceivable hurt to them.

Observation. The study will actualize appropriate safety measures showing that the researcher is working certain perception to individuals within the public place or quasi-public put. The arrangement will be tended to appropriately to avoid any moral issue that might donate undesirable input.

Authorship. The study will give clear and legitimate creation such as origin capabilities, origin credit or based as it were on considerable commitments to conception and plan or securing of information or investigation and elucidation of information. The researcher will look for to draft the article and reexamine it accurately for imperative mental substance and last endorsement of the form to be distributed.

Permission from Organization. The researcher will secure proper permission from the targeted agencies where the respondents are. It will be written in a form of a letter and upon approval. The researcher will gather data according to the scheduled time and set venue.

Technology Issues. Due to the situation that was being experienced right now with no face-to-face conduct of the survey, a google form was used to assess the respondents thought about the study. Zoom and Google meeting was held for consultation and revision of the studies with the adviser.

\section{Results}

Presented in this chapter are the results, interpretation, and analysis of the findings. Results are presented in the following order: level of Sports performance Anxiety among college student-athletes in terms of somatic, worry and concentration disruption; level of sports confidence among college student-athletes in terms of confidence in physical skills and training, confidence in cognitive efficiency, and confidence in resilience; level of friendship quality among college student-athletes in terms of for self-esteem enhancement and supportiveness, loyalty, intimacy, things in common, companionship and pleasant play, conflict resolution and conflict. The significant relationship of sports performance anxiety and sports confidence of student-athletes, the significant relationship of the goal of sports performance anxiety and friendship quality among college student-athletes, the significant relationship of friendship quality and sports confidence, and the significance of the impact of friendship quality on the relationship between sports performance anxiety and sports confidence among college studentathletes. 


\subsection{Level of Sports Anxiety of College Athletes}

The level of sports anxiety of college athletes was interpreted based on the obtained and computed mean rating of its indicators, namely: somatic anxiety, worry and concentration disruption.

As perceived in Table 1, the level of sports anxiety of college athletes revealed a total mean rating of $3.02(S D=0.880)$, labeled as moderate. It can also be viewed from the table that the indicator worry gained the highest mean score of $3.29(S D=0.981)$, described as moderate. It is followed by concentration disruption with mean score of $2.89(S D=0.934)$, descriptively described as moderate. Lastly, the indicator somatic anxiety gained the lowest mean rating with $2.87(S D=0.930)$, described as moderate.

Table 1: Level of Sports Anxiety of College Athletes

\begin{tabular}{|l|c|c|c|}
\hline Indicators & Mean & SD & Descriptive Level \\
\hline Somatic Anxiety & 2.87 & .930 & moderate \\
\hline Worry & 3.29 & .981 & moderate \\
\hline Concentration Disruption & 2.89 & .934 & moderate \\
\hline Overall & $\mathbf{3 . 0 2}$ & $\mathbf{. 8 8 0}$ & moderate \\
\hline
\end{tabular}

Data shows that the moderate level of sports performance anxiety among college athletes in terms of worry is due to the moderate fear that something bad will occur by the decision made. Further, the level of sports performance anxiety among college athletes in terms of concentration disruption is Moderate as the athletes only have a moderate inability to concentrate and a moderate difficulty to focus on something because of some baggage that is running around at his/her thoughts. Lastly, the level of sports performance anxiety among college athletes in terms of somatic was observed to be Moderate which shows that athletes only experienced moderate physical effects such as pain, numbness, and shortness of breath.

\subsection{Level of Sports Confidence of College Athletes}

The level of sports confidence among college athletes has been interpreted accordingly to the obtained mean ratings of the indicators: confidence in physical skills and training, confidence in cognitive efficiency and confidence in resilience.

Table 3: Level of Sports Confidence of College Athletes

\begin{tabular}{|l|c|c|c|}
\hline Indicators & Mean & SD & Descriptive Level \\
\hline Confidence in Physical Skills and Training & 4.02 & .683 & high \\
\hline Confidence in Cognitive Efficiency & 4.19 & .588 & high \\
\hline Confidence in Resilience & 4.04 & .644 & high \\
\hline Overall & $\mathbf{4 . 0 8}$ & $\mathbf{. 5 6 7}$ & high \\
\hline
\end{tabular}

As assessed in Table 3, the level of sports confidence of college athletes revealed a total mean rating of $4.08(S D=0.567)$ labeled as high. It can also be viewed from the table that the indicator confidence in cognitive efficiency gained the highest mean score of 4.19 
$(S D=0.588)$, described as high. It is followed by confidence in resilience with mean score of $4.04(S D=0.644)$, descriptively described as high. Lastly, the indicator confidence in physical skill and training gained the lowest mean rating with $4.02(S D=0.683)$, described as high.

Data shows that the high level of sports confidence among college athletes in terms of confidence in cognitive efficiency is due to the high level of certainty they will be able to be successful in their cognitive sport ability. Further, the level of sports confidence among college athletes in terms of confidence in resilience is High due also to the high athlete's level of certainty they will be able to handle adverse situations. Lastly, the level of sports confidence among college athletes in terms of confidence in physical skill and training was observed to be High which shows that the athlete's level of certainty they will be able to be successful in their physical sport skills is in high point.

\subsection{Extent of Sport Friendship Quality among College Athletes}

The level of friendship quality among college athletes has been interpreted accordingly to the obtained mean ratings of the indicators: self-esteem enhancement and supportiveness, loyalty and intimacy, things in common, companionship and pleasant play, conflict resolution and conflict.

Table 2: Extent of Sport Friendship Quality among College Athletes

\begin{tabular}{|l|c|c|c|}
\hline Indicators & Mean & SD & Descriptive Level \\
\hline Self-esteem Enhancement and Supportiveness & 4.48 & .527 & very high \\
\hline Loyalty and Intimacy & 4.13 & .637 & high \\
\hline Things in Common & 3.93 & .647 & high \\
\hline Companionship and Pleasant Play & 4.48 & .517 & very high \\
\hline Conflict Resolution & 4.24 & .636 & very high \\
\hline Conflict & 3.23 & 1.166 & moderate \\
\hline Overall & $\mathbf{4 . 0 8}$ & $\mathbf{. 4 2 2}$ & high \\
\hline
\end{tabular}

As presented in Table 2, the extent of sport friendship quality among college athletes revealed a total mean rating of $4.08(S D=0.422)$, labeled as high. It can also be viewed from the table that the indicator self-esteem enhancement and supportiveness and companionship and pleasant play gained the highest mean score of $4.48(S D=0.527),(S D=0.517)$, or very High. Followed by conflict resolution with a mean score of $4.24(S D=0.626)$, descriptively described as very high, loyalty and intimacy with a mean score of $4.13(S D=0.627)$, described as high, things in common with a mean score of $3.93(S D=0.647)$, labeled as high, and lastly, conflict with a mean score of $3.23(S D=1.166)$, or moderate.

Results revealed that the college athletes manifest good friendship quality in terms of self-esteem enhancement and supportiveness. This is a reflection of their very high motivation and support to their teammates, especially when given a second chance to perform a skill. Further, the level of friendship quality among college athletes in terms of companionship and pleasant play was also Very High, indicating that the teammates play well together and spend time together. The level of friendship quality among college athletes in terms of conflict resolution is evidently manifested as they exhibit a Very High 
state of believing and understanding to each other just to work things out when disagree. In addition, in terms of loyalty and intimacy, the level of motivation for friendship quality among college athletes is High as their peers stick up for each other and tell each other secrets. Moreover, in terms of things in common, the level of friendship quality among college athletes is High as their teammates have the same values and think in the same way. Lastly, the level of motivation for friendship quality among college athletes in terms of conflict revealed a Moderate level, indicating that members of the team moderately have an argument and get mad at each other.

\subsection{Correlation Analysis of the Variables}

Presented in Table 4 is the correlation analysis of the variables. It can be seen from the table that the correlation between sports anxiety and sports confidence among college athletes gained an overall $r$-value of -0.297 with p-value of 0.000 which is less than the 0.05 level of significance. This indicates that there is a significant relationship between sports anxiety and sports confidence among college athletes. Therefore, the null hypothesis of no significant relationship between sports anxiety and sports confidence among college athletes is rejected.

Moreover, it can also be gleaned from the table that when sports anxiety is correlated with the measures of sports friendship quality among college athletes, the overall r-value results to -0.091 with a p-value of 0.221 which is greater than the 0.05 level of significance. This signifies that sports anxiety does not have a significant relationship with sports friendship quality among college athletes. Therefore, the null hypothesis of no significant relationship between sports anxiety and sports confidence among college athletes do not reject

Table 4: Correlation of the variables, Sports Performance Anxiety, Sports Confidence and Friendship Quality

\begin{tabular}{|l|c|c|c|c|}
\hline Pair & Variable & $\begin{array}{c}\text { Correlation } \\
\text { Coefficient }\end{array}$ & $p$-value & $\begin{array}{c}\text { Decision } \\
\text { on Ho }\end{array}$ \\
\hline IV at DV & $\begin{array}{c}\text { Sports Anxiety and } \\
\text { Sport Confidence }\end{array}$ & -0.267 & $0.000^{* *}$ & Reject \\
\hline IV at ModV & $\begin{array}{c}\text { Sports Anxiety and Sport } \\
\text { Friendship Quality }\end{array}$ & -0.091 & $0.221^{\text {ns }}$ & Do not reject \\
\hline ModV at DV & $\begin{array}{c}\text { Sport Friendship Quality } \\
\text { and Sport Confidence }\end{array}$ & 0.322 & $0.000^{* *}$ & Reject \\
\hline
\end{tabular}

Lastly, Table 4 also reveals the results on the correlation between the measures of sports friendship quality and sports confidence among college athletes. Results revealed that the overall r-value of 0.322 has a p-value of 0.000 which is less than the 0.05 level of significance. This means that sports friendship quality has a significant relationship with the sports confidence among college athletes. Therefore, the null hypothesis of no significant relationship between sports friendship quality and sports confidence among college athletes is rejected. 


\subsection{Moderating Effect of Friendship Quality on the Relationship between Sports Performance Anxiety and Sports Confidence of College Athletes}

Hierarchical linear regression analysis was employed to test the hypothesis on moderating effect. The results of the regression are presented in Table 5.

The independent variable sports performance anxiety was entered in the hierarchical regression procedure as step one. When regressing sports performance anxiety $(\beta=-.154$, $\mathrm{p}<0.01)$, and the moderator variable, friendship quality $(\beta=-.156, \mathrm{p}<0.01)$ in step 2 , they were found to be significant predictors of sports confidence, in their capacities as separate variables.

The third step in the regression analysis was to develop the interaction effect of sports performance anxiety and friendship quality, denoted as anxiety*friendship, to be regressed as a separate regressor of sports confidence in addition to the variables entered in step 1 and step 2. When the effect of one independent variable differs based on the level of magnitude of another variable (i.e., the moderator variable), then an interaction occurs. In this case, the interaction effect of sports performance anxiety and friendship quality is not significant $(\beta=-0.132, p>0.05)$, hence failing to reject the null hypothesis that friendship quality does not significantly moderate the relationship between athletes' sports performance anxiety and sports confidence.

Table 5: Hierarchical Regression to Assess the Moderating Effect of Sport Friendship

Quality on the Relationship of Sport Anxiety and Sport Confidence among Athletes

\begin{tabular}{|c|c|c|c|c|c|c|}
\hline \multirow{2}{*}{\multicolumn{2}{|c|}{ Model }} & \multicolumn{2}{|c|}{ Unstandardized Coefficients } & \multirow{2}{*}{$\mathbf{T}$} & \multirow{2}{*}{ Sig. } & \multirow{2}{*}{$\mathbf{R}^{2}$} \\
\hline & & B & S.E. & & & \\
\hline \multirow{3}{*}{ Step1 } & (Constant) & 2.903 & .413 & 7.031 & .000 & \multirow{3}{*}{0.161} \\
\hline & Anxiety & -.154 & .044 & -3.489 & .001 & \\
\hline & Friendship Quality & .404 & .092 & 4.373 & .000 & \\
\hline & & & & & & \\
\hline \multirow{4}{*}{ Step 2} & (Constant) & 2.885 & .413 & 6.989 & .000 & \multirow{4}{*}{0.167} \\
\hline & anxiety & -.156 & .044 & -3.523 & .001 & \\
\hline & Friendship Quality & .410 & .092 & 4.439 & .000 & \\
\hline & Anxiety * Friendship & -.132 & .114 & 1.152 & .251 & \\
\hline
\end{tabular}

This suggests that the interaction effect did not contribute to the model variance, and that the variables are significant as individual predictors with independent effects towards sports confidence. The result of the study could be further analyzed through the $\mathrm{R}^{2}$ change in Table 5. The $\mathrm{R}^{2}$ change tells how much variance of sports confidence these predictors explain each of the steps. The $\mathrm{R}^{2}$ change in step 2 is 0.167 , which increased from 0.161 in step 1. This means that there is an additional $0.06 \%$ in the addition of the moderator variable in step 2 . This means that the interaction has a negligible contribution to sports confidence.

To validate the result of the regression, a mod graph (Figure 3) was generated from the interaction data as displayed in Table 6. The graph shows low anxiety with high friendship quality has the highest mean score of 4.3582, which is described as high. It is 
followed by low anxiety with moderate friendship quality with a mean score of 2.6561, which is described as moderate. Lastly, low anxiety with low friendship quality has the lowest mean score of 4.1319 , which is described as high.

Table 6: Summary of Means of College Athletes' Sport Confidence from the Effects of Sports Anxiety and Sport Friendship Quality

\begin{tabular}{|l|c|c|c|}
\hline & $\begin{array}{c}\text { Low Friendship } \\
\text { Quality }\end{array}$ & $\begin{array}{c}\text { Moderate Friendship } \\
\text { Quality }\end{array}$ & $\begin{array}{c}\text { High Friendship } \\
\text { Quality }\end{array}$ \\
\hline Low Anxiety & 4.1319 & 4.2657 & 4.3582 \\
\hline Average Anxiety & 3.9116 & 4.1122 & 4.2508 \\
\hline High Anxiety & 3.7139 & 3.9743 & 4.1543 \\
\hline
\end{tabular}

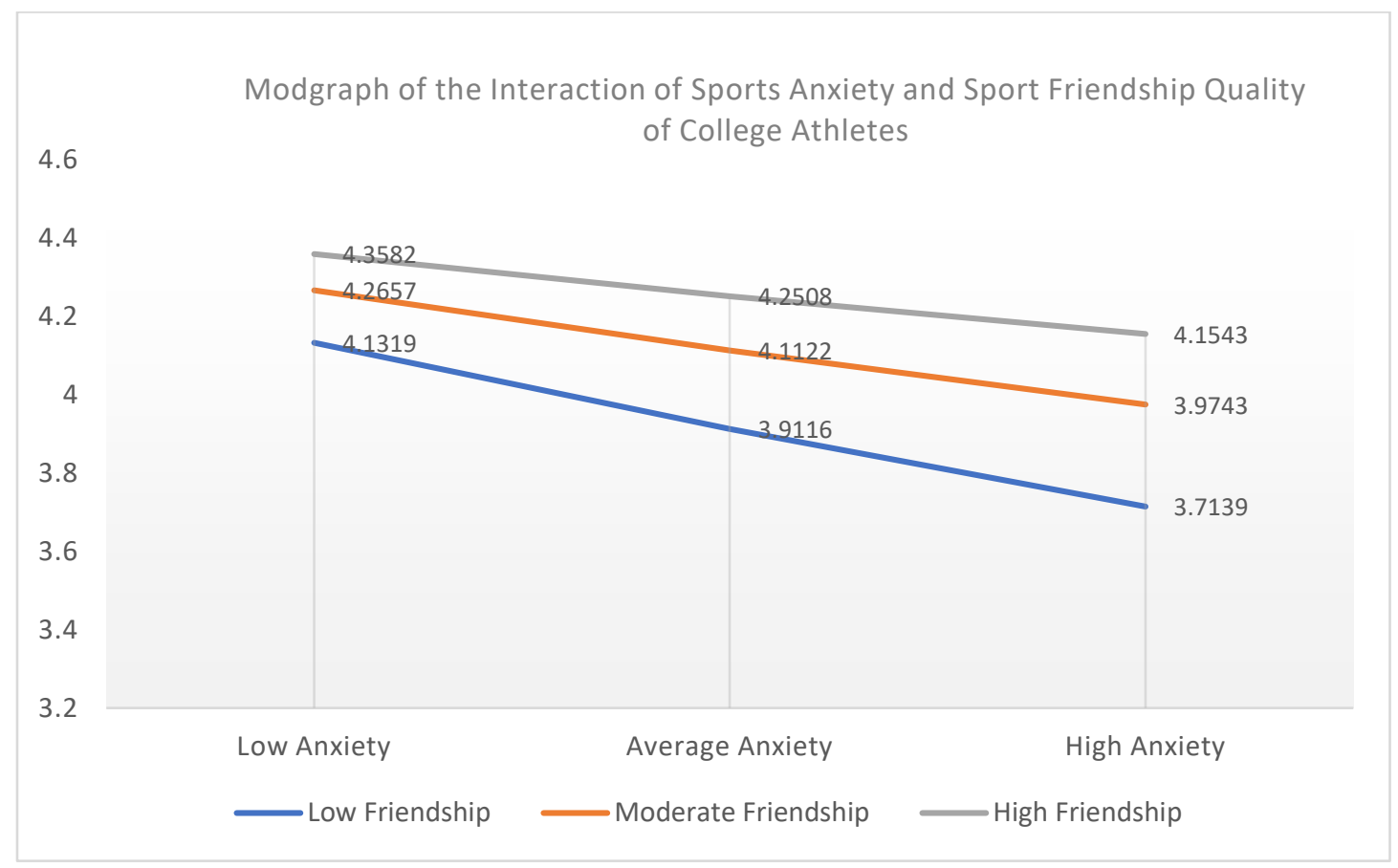

Figure 3: Graphical Depiction of the Moderating Effect of Sport

Friendship Quality on Sports Anxiety-sport Confidence Relationship

Furthermore, average anxiety with high friendship quality has the highest mean score of 4.2508, which is described as high. It is followed by average anxiety with moderate friendship quality with a mean score of 4.1122, which is described as high. Lastly, average anxiety with low friendship quality got the lowest score of 3.9116, which is described as high. On the other hand, high anxiety with high friendship quality has the highest mean score of 4.1543 , which is describe as high. It is followed by high anxiety with moderate friendship quality with a mean score of 3.9743, which is describe as high. Lastly, high anxiety with low friendship quality got the lowest mean score of 3.7139, which is describe as high. 


\section{Discussion}

This chapter presents the discussion and conclusion of the data on Sports Performance Anxiety, Sports Confidence, and Friendship Quality among college athletes. Also, recommendations are presented in this chapter.

\subsection{Sports Performance Anxiety}

The level of sports performance anxiety of student-athletes is moderate, resulting from the adequate levels responses. The indicators, worry, concentration disruption and somatic have moderate ratings. These indicators are arranged from highest to lowest level.

- The moderate rating of worry is suggestive of the moderate fear of the studentathlete that something bad will occur by the decision made. This is in line with the statements by Dunn et al. (2018) which affirmed that as student-athlete highly think that they are not competitive right before the competition giving them doubts about the position, leading to a loophole full of worries. These tendencies are often caused with lack of self-esteem especially in terms of believing in their own capabilities or being overwhelmed by their opponent or competitor. Further, these student-athlete may have someone willingly to listen to whatever problems it may be as it is a great remedy since people are not destined to be alone. Advice, sympathy and empathy are strong enough to heal student-athletes slowly but surely (Robinson, Smith, Segal, \& Segal, 2019).

- Moreover, the moderate level of concentration disruption is suggestive that studentathletes only have a moderate inability to concentrate and a moderate difficulty to focus on something because of some baggage that is running around at his/her thoughts. This is in line with the statements by Stoppler (2019) which expressed that tiredness and emotional stress are two of the common cause of the inability to concentrate and only some student-athlete may result in Attention-Deficit Hyperactivity Disorder which is more serious than concentration disruption. Additionally, as student-athletes exercise and have a healthy diet, it can energize them to be involved in their everyday life. It is important to have a healthy lifestyle to collect some energy needed for daily activities (Hallowell, 2014).

- Lastly, the indicator somatic revealed a moderate level indicative of that studentathlete experiencing only moderate physical effects such as pain, numbness, and shortness of breath. This claim concurs with the statements by Cleveland Clinic (2018) which stated that as only those student-athletes handling substance or alcohol abuse, neglect during childhood, abuses both physical and sexual, trauma, chronic illness during childhood, psychiatric disorders, and heightened attention to bodily sensations are most likely going to experience this kind of disorder. Student-athletes are also given possibilities to release negativities as it is far better compared to some methods that exploit their creativity and probably use their negativity for the better (Henningsen, 2018). 


\subsection{Sports Confidence}

The other variable used in this study is sports confidence among college athletes. The highlevel results from the high-level ratings of the respondents. The indicators confidence in cognitive efficiency, confidence in resilience and confidence in physical skills and training were arranged from highest to lowest.

- The high level of confidence in cognitive efficiency is a reflection of the athlete's level of certainty they will be able to be successful in their physical sport skills. This is in line with the statements by Taylor (2020) which affirmed that having confidence in sports involves having self-confidence, which is your trust and willingness to achieve a desired physical prowess or function in your sport. At instances, our confidence can be strengthened by the confidence of others in us; however, essentially, we have to believe from our own capacities to go over there and do our best. Additionally, through having sports confidence an athlete can lower and measured up the pressure of what anxiety in a game can provide, which gives great results in performance (Craft, 2013).

- Furthermore, the high level of confidence in resilience is indicative that this was the athlete's level of certainty they will be able to handle adverse situation's ability. This is in line with the study of Lombardo et al., (2018) which expressed that sportconfidence makes a difference competitor to control and diminish negative feelings particular to athletic competition like sports anxiety. This capability strengthens the athlete's sense of dominance and justification amid the game and progresses his/her sports execution. Sports confidence plans competitors for dynamic experiencing with sports anxiety through fortifying proficient adapting procedures. Utilizing productive adapting methodologies for sports anxiety assist the athlete to control and oversee unpleasant circumstance way better, and through this, there will be progress in his/her athletic execution (Pourbohlool, S., 2018).

- Lastly, the high level of confidence in physical skills and training indicates the athlete's level of certainty they will be able to be successful in their physical sport skills. This is in line with the study by Chandel (2018) which states the maturity level of trusting the ability will be far beyond the normal state of an athlete, described as the sport confidence wirelessly on the assumption or level of conviction an athlete has about their ability to succeed in sports. In fact, having body conditioning physically as advised by coaches can greatly enhance sports confidence towards playing and competing (Gould, 1989).

\subsection{Friendship Quality}

The third variable considered in this study is friendship quality among student-athletes which was described as high. The high level of friendship quality among student-athlete results from the high-level ratings of the respondents. The indicators self-esteem enhancement and supportiveness, companionship and pleasant play, conflict resolution, loyalty and intimacy, things in common and conflict were arranged from highest to lowest. 
The high-level rating of self-esteem enhancement and supportiveness is suggestive of the high focus on giving assistance to the teammates. This is in line with the statements of Cox, (2017) which state that individual athlete boosts up their self-esteem whenever they feel believed by their teammates, more happiness in activities and want to participate whenever there is an activity. Thus, the great way to bond with others is to play together with the team (Raglin, 2010).

- The high level of companionship and pleasant play is due to the high feeling of fellowship and friendship of student-athletes towards their team members. This is in line with the statements by Asher \& Dodge (2019) which expressed that looking at peer relations make it clear that companions apply a major impact on youth psycho-social advancement and behavior. Meanwhile, an expansive body of sport psychology inquiries highlights the imperative part that companions play in inspiration competence advancement, sport delight and commitment, and character and ethical improvement. For illustration, competence in sport is connected to social status, ubiquity, and peer acknowledgment, and companionship is related to positive influence (e.g., satisfaction) in physical movement (Smith, 2017).

- Moreover, the very high level of conflict resolution is suggestive that studentathletes have a very high quality of being determined in resolving team gameplay and problem among the group. This is in line with the statements by Englert \& Bertrams, (2012) states that a game experience of athletes can make teamwork wonderful and can enhance the concern with the principles of right and wrong behavior of a matured workgroup. You learn a lot and continue absorbing knowledge and wisdom whenever you are part of them and feel the state of belongingness to a particular group. In like manner, it has been recognized that measurements of friendship quality may have vital suggestions for motivation related result factors within the setting of sport (Weiss and Smith, 2016).

- Furthermore, the high level of loyalty and intimacy is due to the high level of a feeling of support or allegiance of a student-athlete respecting his/her teammate. This concurs with the study by Bartholomew, (2017) which concludes that two people who are shakily connected and thus more likely to hold negative working models of themselves and others within the setting of connections, will have more noteworthy issues with closeness and the arrangement of near bonds within the peer bunch than will more safely connected people.

- In addition, the high level of things in common is due to the high level of the same state wanting to learn about something or someone in a teammates interest. This concurs with the study by Wrzus, (2017) which state that there is a natural attraction that pulls together people with similar interests, beliefs, and lifestyles. These similarities create a chemistry that makes it easier to form friendships and close relationships with others. While this chemistry sometimes happens naturally, it can also be created intentionally when people are able to find things in common with each other. 
- Lastly, the moderate level of conflict is due to the moderate level of a serious disagreement or argument, typically a protracted one in the group. This concurs with the study by D'agati, (2018) that even if your team doesn't voice conflict, it's inevitable. If a team is so conditioned to pretend conflict doesn't exist, there's a problem in communication and the team will ultimately suffer. Besides, whether your athletes are shouting at each other, not speaking at all, or fighting on the field, conflict is a natural part of any team dynamic (Thorpe, H., 2021).

\subsection{Correlation Analysis of the Variables}

- The correlation between measures of sports performance anxiety and sports confidence among student-athletes revealed a significant relationship. This implies that sports performance anxiety is significantly correlated with sports confidence among student-athlete. The findings of this study confirm with the studies of various authors Kang, H., \& Jang, S. (2018) which have shown that individuals with high levels of sports confidence report low anxiety levels, which suggests that sports confidence and anxiety are inversely related. Which explain to a sample of windsurfers, that those athletes who experienced less somatic anxiety had higher overall rankings, and that those who were listed as members of the "top five" also had higher self-confidence than lower-ranked athletes (Modroño \& Guillén, 2012). Lastly, the relationship of sports anxiety and sports confidence can be explained even in a game of the home and away, where athletes report higher self-efficacy and sports confidence and lower cognitive and somatic anxiety prior to home games as opposed to away (Marshall, E. A., \& Gibson, A. M., 2017).

- On the other hand, the correlation between measures also revealed that there is no significant relationship between sports performance anxiety and friendship quality among student-athletes. This implies that sports performance anxiety is negatively correlated with friendship quality among student-athletes. This claim negates with the studies of various authors Rocamora, I., et al., (2019) stated that for many athletes, participating in team sports and competition is a source of positive interaction. Such involvement can be fun, exciting, and a potential vehicle for personal achievement and friendship quality. For some athletes, however, the excitement of having fun with teammates, and the challenge of sports involvement and competition often are accompanied or supplanted by anxiety and stress. Such individuals typically become tense and apprehensive prior to or during competition. Instead of focusing on the task before them, they become preoccupied with sports anxiety and worry (Pluhar, Emily, et al., 2019). With this, it explains the relation of sports anxiety and friendship quality a not significant and correlated, that with the common mantra of having friends in sports releases stress could fall to reverse outcome in giving more anxiety due to high level of competitive sports anxiety (Stavropoulou, G., \& Stavropoulos, N. 2021).

- Lastly, the correlation between the measures of sports friendship quality and sports confidence among student-athletes revealed a significant relationship. This implies 
that sports friendship quality is significantly associated with sports confidence among student-athletes. The findings of this study confirm with the studies of various authors Herbison, et al., (2017) which states that when peers and friends in a sports praise or recognize the skills and capabilities in a certain playing area, it can boost the confidence in playing sports, as long as the athlete believes the good things, too. By this, the relationships that athletes develop during sport can lead to a lot of different outcomes. For example, when a player feels accepted by their peers, they report higher levels of sports confidence, more enjoyment of activities and are less likely to want to avoid participating (Dumon, Detlef, et al., 2017). And so, with the complementation coming from a teammate or a friend even if they aren't expecting it, it will have an immediate impact on the sports confidence and performance of an athlete. The friendship quality of hearing something positive and reassuring is a good way to give peers and athletes a boost in performance (Rocamora, I., et al., 2019).

\subsection{Moderation Analysis of the Three Variables}

The aim of this study is to contribute to the literature regarding the possible indirect, moderating variable for the relationship between sports performance anxiety and sports confidence among student-athlete. Specifically, sports friendship quality among studentathlete was investigated as a possible moderating variable that could explain the effect of sports performance anxiety on sports confidence among student-athlete. However, only little to no moderation at all is found in the study. Important and significant direct effects were also presented that may help in the enhancement of the existing researches on sports performance anxiety and sports confidence among student-athlete. Significantly, the studies of these authors on the relationship of sports performance anxiety and friendship quality among student-athletes support the theory of Bouras (2012) which states that unhappily, with the various academic findings, athletes can sometimes experience negativity towards friends and peers in sports. Particularly, they isolate other athletes for their own good; they start in rumors then ignore one another and come to a time where an athlete refuses to pass the ball to the teammate. The attachment theory of Bowlby (1973) expressed that in sport psychology, attachment theory has recently been utilized to understand how athletes see and adapt with fears and tensions, wounds, and execution droops (Sports Performance Anxiety) through individual connections (athlete to athlete) offer assistance to their teammates to either prosper and boost sports performance.

Moreover, the current study has found that friendship quality among studentathlete is a negative and not a significant moderator of sports performance anxiety and sports confidence among student-athlete and did not meet Memon (2019) moderation guidelines. The moderation analysis involved the path between sports performance anxiety and sports confidence among student-athletes and the path between friendship quality and the relationship between sports performance anxiety and sports confidence among student-athlete. The findings negate the significant relationship between sports performance anxiety and friendship quality among student-athletes leading to negate 
one of the authors of this study Cox (2017), which stated that an individual athlete boosts up their self-esteem and somehow neglect all their worries whenever they feel believed by their teammates, more happiness in activities and want to participate whenever there is an activity.

\subsection{Recommendations}

The researcher came up with recommendations based on the results of the study. On the moderate level data result of Sports Performance Anxiety, the coaches or sports directors may introduce different techniques on how to overcome stresses and pressures being experienced by the student-athletes. One-on-one counseling may be conducted to student-athletes who have some anxieties to address individual differences or existing problems among students. The sports director may allow the conduct of sports competition among the student-athlete starts locally or if the situation warrants an interschool competition in order to boost the morale of the student-athlete and feel proud of their achievements in their field of expertise or talents. The giving of recognition and commendations to players for best achievement or performances may be done through the awarding of medals and certificates during recognition or graduation ceremonies.

On the high-level data result of sports friendship quality, it is recommended that the sports directors and school management may continue to create an atmosphere of camaraderie and teamwork among the student-athlete in practices and sports clinics by regularly providing them with updates on specified sporting events through the conduct of re-orientation and relevant seminars and workshop on topics discussed during their training booth camp. There may be once a month conduct of skills clinic to allow the student-athlete to be motivated and have energy while performing sports drills in their specified events. In this way, new skills and techniques may be acquired by the studentathlete at the end of the season and the student-athlete is able to maintain their body physique and appearance all through the league and sports competition.

In order to improve the existing facilities in school, it is recommended that a specific budget for the purchase of sports paraphernalia may be allotted. This will provide a good image of the school and will attract more student-athlete to be motivated to perform their best in sports and other physical activities. In addition, through this, it will maintain the high or even increase the data result in sports confidence among student-athletes. Also, if funds warrant, the school may grant scholarships to deserving students or incentives and discounts to student-athletes who are performing well in their fields.

\subsection{Conclusion}

With consideration of the findings of the study, conclusions are drawn in this section. The findings of the study clearly negate the notion about the moderating effect of sports friendship quality among student-athletes on the relationship between sports performance anxiety and sports confidence of student-athlete. The findings negate the attachment theory (Bowlby, 1973) which expressed that in sports psychology, attachment 
theory has recently been utilized to understand how athletes see and adapt with fears and tensions, wounds, and execution droops (Sports Performance Anxiety) through individual connections (athlete to athlete) offer assistance to their teammates to either prosper and boost sports performance.

Moreover, there is a significant relationship between sports performance anxiety and sports confidence among student-athlete. Also, sports friendship quality has a significant relationship with sports confidence among student-athlete. However, sports performance anxiety does not have a significant relationship with sports friendship quality. Lastly, there is no moderating on effect of sports friendship quality on the relationship between sports performance anxiety and sports confidence among studentathlete.

\section{Acknowledgement}

No one walks alone in the journey of life and while you are at it. Start thanking those who joined you, walk beside you, and helped you along the way.

I am so proud to acknowledge and extend my heartfelt gratitude to the following persons who made the completion of this research:

First, I would like to thank my family who supported and financed me all the way through the making of this paper possible.

Second, I would like to show my greatest appreciation to all my professors. No words can describe how grateful I am for your tremendous support and help. I feel so motivated and encouraged at the moment I attend to their classes. It is through their teaching, encouragement and support that I have gained and grown.

Third, a special thanks to my adviser, Rodolfo II M. Osorno Ed.D, for his uncomplaining and unconditional assistance in checking and her guidance to make this easy and possible.

Fourth, the Panel of Examiners chaired by Dr. Jocelyn Bacasmot, and the members, Dr. Mary Ann Tarusan, Dr. Pedrito Castillo, and Dr. Lovella Serano, of their comments and suggestions.

Fifth, I would like to acknowledge the President of Davao del Sur State College, Dr. Augie E. Fuentes and the President of Southern Philippines Marine and Aquatic School of Technology, Dr. Ruth Lucero for their permission in conducting this study.

Sixth, the professional person who guide me in the process of completing this masterpiece, Dr. John Vianne Murcia, thank you so much for giving suggestions, comments and insights you really did a crucial part in the completion of this research.

Eight, I would like to thank my partner Lorraine Leigh Lacumba who are always there to motivate and inspire me with the succeeding days of completing this research.

And finally, to God the Father of all, I thank you for the strength that keeps me standing and for the hopes that keep me believing that this thesis would be possible and hopefully would help many athletes in dealing with good preparation that may result in an excellent performance. 


\title{
Conflict of Interest Statement
}

The authors declare no conflicts of interests.

\begin{abstract}
About the Authors
Prof. Gideon Juezan is a college instructor at Davao del Sur State College, Philippines. A Sports Director and an Athletics Coach. His Main research interest is in the area of Factors affecting athletes' performance.
\end{abstract}

Dr. Rodolfo II M. Osorno is a University of Mindanao Digos campus college professor, Master Teacher 1 Ramon Magsaysay Central Elementary School. His main research interest is in the area of the education system.

\section{References}

Angulo-Meza F. (2013). A data envelopment analysis evaluation and financial resources reallocation for Brazilian Olympic sports. WSEAS Transactions on Systems, 12(12), 627-636.

Asher, S. R., \& Dodge, K. A. (2019). Identifying children who are rejected by their peers. Developmental Psychology, 22, 444-449.

Bandura, A. (1986). Social foundations of thought and action. Englewood Cliffs, NJ: Prentice Hall.

Bandura, A. (1997). Self-efficacy: The exercise of control. New York: Freeman.

Bartholomew, K. (2017). Avoidance of intimacy: an attachment perspective. Journal of Social and Personal Relationships, 7, 147-178.

Bouras T. (2012). Perceived impact of anger and anxiety on sporting performance in rugby players. Psychology of sport and exercise, 8(6), 875-896.

Bowlby, J. (1973). Attachment and loss: Vol. 1. Attachment (2nd ed.). New York: Basic Books.

Boyd, M., \& Zenong G. (2018). Pedagogy of emergency and vulnerability: testing of a Mental Skill Training protocol. Giornale Italiano di Educazione alla Salute, Sport e Didattica Inclusiva, 4(4_sup).

Chandel, S. (2018). Evaluation and comparison of state sports confidence between Punjab and Madhya Pradesh Cricket teams of Under 19.

Cleveland Clinic (2018). Somatic symptom disorder in adults. Retrieved from https://my.clevelandclinic.org/health/diseases/17976-somatic-symptom-disorderin-

adults\#: :text=Somatic $\% 20$ symptom $\% 20$ disorder $\% 20$ is $\% 20$ a,based $\% 20$ on $\% 20$ the \%20patient's\%20complaint.

Cohn, D. A. (2019). Child-mother attachment of six-year-olds and social competence at school. Child Development, 61(1), 152-162.

Coie, I. D., \& Cillessen, A. H. N. (2019). Peer rejection: origins and effects on children's development. Current Directions, 2, 89-92. Companies Inc., New York, USA.

Cox R. H. (2017). Sport psychology: Concepts and applications. McGraw Hill. 
Craft T. (2013). Surrogate war: politics of conflict in sports and space. International Journal of Sport Policy and Politics, 10(3), 451-467.

Craft, L. L., Magyar, T. M., Becker, B. J., \& Feltz, D. L. (2016). The relationship between the Competitive State Anxiety Inventory-2 and sport performance: A metaanalysis. Journal of Sport and Exercise Psychology, 25, 44-65.

D'agati, P. A. (2018). Surrogate war: politics of conflict in sports and space. International Journal of Sport Policy and Politics, 10(3), 451-467.

Dumon, D., Detlef, et al. (2017). Passionately inclusive: towards participation and friendship in sport: Festschrift für Gudrun Doll-Tepper. Waxmann Verlag.

Dunn, J. G. H., et al. (2018). Perfectionism, pre-competitive worry, and optimism in high performance youth athletes. Retrieved from https://www.tandfonline.com/doi/abs/10.1080/1612197X.2019.1577900?journalCo $\underline{\text { de}}=$ rijs2

Englert, C., \& Bertrams, A. (2012). Anxiety, ego depletion, and sports performance. Journal of Sport and Exercise Psychology, 34(5), 580-599.

Feltz, D. (2018). Self-confidence and sport performance. In K.B. Pandolf (Ed.), Exercise and Sport Science Reviews, 16, 423-457.

Feltz, D. L., \& Mugno, D. A. (1983). A replication of the path analysis of the causal elements in Bandura's theory of self-efficacy and the influence of autonomic perception. Journal of Sport and Exercise Psychology,5(3), 263-277. female athletes. Journal of pediatric and adolescent gynecology, 23(6), 325-335.

Frischknecht, A., et al. (2016). Noninvasive Estimation of Hydration Status in Athletes Using Wearable Sensors and a Data-Driven Approach Based on Orthostatic Changes. Sensors, 21(13), 4469.

Frischknecht, G., Pesca, A. D., \& Cruz, R. M. (2016). Adaptation and validation of sportconfidence measure to gymnasts and football players. Psico-USF, 21, 539-549.

Gagnon-Dolbec, A., McKelvie, S. J., \& Eastwood, J. (2019). Feedback, sport-confidence and performance of lacrosse skills. Current Psychology, 38(6), 1622-1633.

Giles, L. C., Glonek, G. F. V., Luszcz, M. A., \& Andrews, G. R. (2019). Effect of social networks on 10 year survival in very old Australians: The Australian longitudinal study of aging. Journal of Epidemiology \& Community Health, 59, 574- 579. doi:10.1136/jech.2004.025429

Gould, D. (1989). An exploratory examination of strategies used by elite coaches to enhance self-efficacy in athletes. Journal of Sport \& Exercise Psychology, 11, 128-140.

Hallowell, E. (2014). 5 reasons you can't focus and what to do about it. Retrieved from https://www.fastcompany.com/3038977/5-reasons-you-cant-focus-and-what-todo-about-it

Hartup, W. W. (2019). Constraints on peer socialization: Let me count the ways. MerrillPalmer Quarterly, 45, 172-183. higher-order catastrophe models? An exploratory analysis. Journal of Sport and Exercise Psychology, 26, 359-368.

Hays, K., et al. (2007). Sources and types of confidence identified by world class sport performers. Journal of applied sport psychology, 19(4), 434-456. 
Henningsen, P. (2018). Management of somatic symptom disorder Peter Henningsen, MD*. Retrieved from https://www.ncbi.nlm.nih.gov/pmc/articles/PMC6016049/

Herbison, J. D., et al. (2017). Intricacies of the friendship-cohesion relationship in children's sport. Sport \& Exercise Psychology Review, 13(1), 10-19.

Humara M. (2018). The relationship between anxiety and performance: A Cognitive in sport and exercise psychology measurement (pp. interpretation. Journal of Sports Sciences, 19, 385-395. doi:10.1080/026404101300149348

Kang, H., \& Jang, S. (2018). Validation of a Questionnaire that Surveys Confidence in Sports among Korean Competitive Athletes. Journal of Men's Health, 14(2), e30-e41.

Ladd, G. W. (2019). Peer relationships and social competence during early and middle childhood. Annual Review of Psychology, 50, 333-359.

Lombardo, E. R., et al. (2018). Anger management style and association with self-efficacy and pain in male veterans. The Journal of Pain, 6, 765-770. doi:10.1016/j.jpain.2005.07.003

Machida, M., Otten, M., Magyar, T. M., Vealey, R. S., \& Ward, R. M. (2017). Examining multidimensional sport-confidence in athletes and non-athlete sport performers. Journal of Sport Sciences, 35(5), 410-418.

Magyar, T. M., \& Feltz, D. L. (2003). The relationship between the Competitive State Anxiety Inventory 2 and sport performance: A meta-analysis. Journal of sport and exercise psychology, 25(1), 44-65.

Marshall, E. A., \& Gibson, A. M. (2017). The effect of an imagery training intervention on self-confidence, anxiety and performance in acrobatic gymnastics-a pilot study. Journal of Imagery Research in Sport and Physical Activity, 12(1).

Martens T. \& Burton S. (2019). The relationships among competitive orientation, sportconfidence, self efficacy, anxiety, and performance. Journal of Sport and Exercise Psychology, 13(2), 149-159.

Martens, R. (2017). Coaches guide to sport psychology. Champaign, IL: Human Kinetics.

Martens, R., et al. (2007). Development and validation of the Competitive State Anxiety Inventory-2. In Competitive Anxiety in Sport (edited by R. Martens, R.S. Vealey and D. Burton), pp. 117-190. Champaign, IL: Human Kinetics.

Martin, S., \& McHendry Jr, G. F. (2016). Kaepernick's Stand: Patriotism, Protest, and Professional Sports. Journal of Contemporary Rhetoric, 6.

McArdle, S., \& Duda, J. K. (2014). Implications of the motivational climate in youth sports. In F. L. Smoll \& R. E. Smith (Eds.), Children and youth in sport: A biopsychosocial perspective (2nd ed., pp. 409 434). Dubuque, IA: Kendall/Hunt.

Memon, M. (2019). Predictors of outcomes after hip arthroscopic surgery for femoroacetabular impingement: a systematic review. Orthopaedic journal of sports medicine, 7(6), 2325967119848982.

Michael, J. P. (2011). Injuries and overuse syndromes in powerlifting. International journal of sports medicine, 32(09), 703-711. 
Modroño, S., Soldado, A., Martínez-Fernández, A., \& de la Roza-Delgado, B. (2012). Handheld NIRS sensors for routine compound feed quality control: Real time analysis and field monitoring. Talanta, 162, 597-603.

Orlick, T. (2017). The role of sport psychology consultants in protecting young athletes from harm. Sport psychology for young athletes, 243.

Patel, D. R., Omar, H., \& Terry, M. (2010). Sport-related performance anxiety in young female athletes. Journal of pediatric and adolescent gynecology, 23(6), 325-335.

Pluhar, E., et al. (2019). Team sport athletes may be less likely to suffer anxiety or depression than individual sport athletes. Journal of sports science \& medicine, 18(3), 490.

Pourbohlool, S. (2011). Moderating effects of self-confidence and sport self-efficacy on the relationship between competitive anxiety and sport performance. Psychology, 2(07), 760.

Pourbohlool, S. (2018). Enhancing physical education and sport science students' selfefficacy and attitudes regarding information and communication technologies through a computer literacy course. Computers and Education, 54, 298-308. doi:10.1016/j.compedu.2009.08.015

Radochoński, M., Cynarski, W., Perenc, L., \& Siorek-Maślanka, L. (2019). Competitive The perception of stress: A potential source and its development. In M.R. Weiss \& D. Gould (Eds.), Sport for children and youths (pp. 119-126). Champaign, IL: Human Kinetics.

Raglin J. S. (2010). Competitive trait anxiety among male and female junior high school athletes. International Journal of Sport Psychology, 18, 171-180. regions (Vol 2). Cambridge University Press, New York, USA. relationship with self-confidence performance: A qualitative explanation. Research Quarterly for Exercise and Sport, 73, 87-97.

Robinson R. (2015). The mental health benefits of exercise. Retrieved January, 25, 2020.

Robinson, Smith, Segal, \& Segal, (2019). Physical activity levels, game performance and friendship goals using two different pedagogical models: Sport Education and Direct Instruction. Physical Education and Sport Pedagogy, 24(1), 87-102.

Rocamora, I., et al. (2019). Physical activity levels, game performance and friendship goals using two different pedagogical models: Sport Education and Direct Instruction. Physical Education and Sport Pedagogy, 24(1), 87-102.

Rubin M., \& Bukowski T. (2019). Social information processing and coping strategies of shy/withdrawn and aggressive children: Does friendship matter?. Child development, 77(2), 371-383.

Rubin, K. H., et al. (2017). Social information processing and coping strategies of shy/withdrawn and aggressive children: Does friendship matter?. Child development, 77(2), 371-383.

Scoffier-Mériaux, S., Maiano, C., \& D'Arripe-Longueville, F. (2009). Factor validity and reliability of the sport friendship quality scale in a French adolescent sample. International Journal of Sport Psychology, 40, 324-350. 
Sedarati, M. (2017). Effect of different pre-competition anxiety and self-confidence on the performance in bouldering climbers. Gaziantep Üniversitesi Spor Bilimleri Dergisi, 3(1), 1-9.

Smith V. (2017). Sport performance anxiety in children and youth. In F. L. Smoll \& R. E. Smith (Eds.), Children and youth in sports: A biopsychosocial perspective (2nd ed., pp. 501-536). Dubuque, IA: Kendall/Hunt.

Smith, et al. (2006). Enhancement of children's self-esteem through social support training for youth sport coaches. Journal of Applied Psychology, 78, 602-610.

Smith, R. E., Smoll, F. L., Cumming, S. P., \& Grossbard, J. R. (2006). Measurement of multidimensional sport performance anxiety in children and adults: The Sport Anxiety Scale-2. Journal of Sport and Exercise Psychology, 28(4), 479-501.

Smith, R. E. (2018). Measurement and correlates of sport-specific cognitive and somatic trait anxiety: The Sport Anxiety Scale. Anxiety Research, 2, 263280.

Smith, R. E. Ptacek, J. T. \& Patterson, E. (2000). Moderator effects of cognitive and somatic trait anxiety on the relation between life stress and physical injuries. Anxiety, Stress, and Coping, 13, 269-288.

Sonstroem, R. J. and Bernardo, P. (2018). Intraindividual pregame state anxiety and basketball performance: a reexamination of the inverted-U curve. Journal of Sport Psychology, 4, 235-245

Stavropoulou, G., \& Stavropoulos, N. (2021). Association between team sports and anxiety with reaction time of individuals with visual impairment versus individuals with normal vision. Trends in Sport Sciences, 28(2).

Stoppler, M. (2019). Difficulty concentrating: Symptoms \& Signs. Retrieved from https://www.medicinenet.com/difficulty concentrating/symptoms.htm

Taylor V. (2020). Self Confidence and Performance. Retrieved from https://metrifit.com/blog/good-preparation-breeds-confidence/

Thorpe, H. (2021). Informal sports for youth recovery: Grassroots strategies in conflict and disaster geographies. Journal of Youth Studies, 24(6), 708-730.

Tillfors, M., Persson, S., Wille'n, M., \& Burk, W. J. (2018). Prospective links between social anxiety and adolescent peer relations. Journal of Adolescence, 35, 1255- 1263. doi:10.1016/j.adolescence.2012.04.008

Ullrich-French, S., \& Smith, A. L. (2017). Perceptions of relationships with parents and peers in youth sport: independent and combined prediction of motivational outcomes. Psychology of Sport and Exercise, 7, 193-214.

Vealey, R. (1986). Conceptualization of sport-confidence and competitive orientation: Preliminary investigation and instrument development. Journal of Sport Psychology, 8, 221-246.

Vealey, R. (1988). Sport-confidence and competitive orientation: An addendum on scoring procedures and gender differences. Jouml of Sport \& Exercise Psychology, $10,471-478$. 
Vealey, R. S., \& Chase, M. A. (2008). Self-confidence in sport: Conceptual and research advances. In: T. S. Horn (Ed.), Advances in sport psychology (3rd ed., pp. 65-97). Champaign, IL: Human Kinetics.

Vealey, R. S., Garner-Holman, M., Hayashi, S. W., \& Giacobbi, P. (1998). Sources of sportconfidence: Conceptualization and instrument development. Journal of Sport and Exercise psychology, 20(1), 54-80.

Weinberg (Weinberg, Robert Stephen), \& Gould, D. (2011). Foundations of Sport and Exercise Psychology: Welcome to Sport and Exercise Psychology; Chapter 2. Personality a Sport; Chapter 3. Motivation; Chapter 4. Arousal, Stress, and Anxiety; Chapter 5. Competition and Cooperation; Chapter 6. Feedback, Reinforcement, and Intrinsic Motivation; Chapter 7. Group and Team Dynamics; Chapter 8. Group Cohesion; Chapter 9. Leadership; Chapter 10. Communication. Human Kinetics.

Weinberg, R. S., \& Gould, D., (2011). Expectancies and performance: An empirical test of Bandura's self-efficacy theory. Journal of Sport Psychology, 1, 320- 331.

Weiss, M. R., \& Smith, A. L. (2016). Quality of youth sport friendships: measurement development and validation. Journal of Sport \& Exercise Psychology, 21, 145-166.

Weiss, M. R., \& Smith, A. L. (2017). Friendship quality in youth sport: relationship to age, gender, and motivation variables. Journal of Sport \& Exercice Psychology, 24, 420437.

Weiss, M. R., et al. (2018). "That's what friends are for": children's and teenagers' perceptions of peer relationships in the sport domain. Journal of Sport \& Exercise Psychology, 18, 347-379.

Williams, J. M., \& Scherzer, C. B. (2006). Injury risk and rehabilitation: Psychological considerations. In J.M. Williams (Ed.), Applied sport psychology: Personal growth to peak performance (5th ed., pp. 565594). Boston, MA: McGraw-Hill.

Wilson, et al. (2004). Sources of sport confidence of master athletes. Journal of Sport and Exercise Psychology, 26(3), 369-384.

Wrzus, C., Zimmerman, J., Mund, M., \& Neyer, F. J. (2017). Friendships in young and middle adulthood. In M. Hojjat \& A. Moyer (Eds.), The Psychology of Friendship (pp. 21-38). Oxford University Press.

Wuff, G., \& Toole, T. (2017). Physical assistance devices in complex motor skill learning: benefits of a self-controlled practice schedule. Research Quarterly for Exercise and Sport, 70 (3), 265-274.

Yavuz, C. (2019). The Relationships among Attitude towards Sports, Loneliness and Happiness in Adolescents. Universal Journal of Educational Research, 7(3), 790-796. 


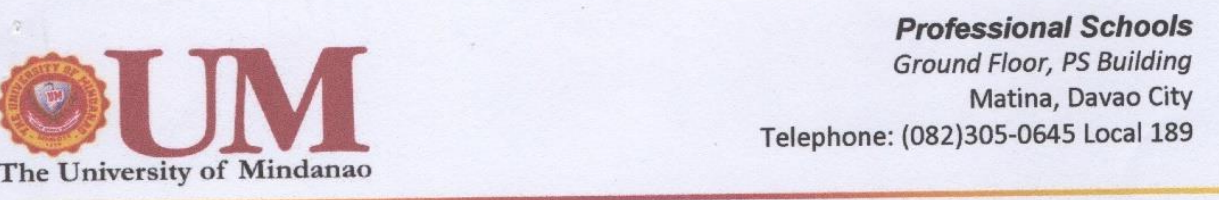

April 22, 2021

\section{AUGIE E. FUENTES, Ph.D}

President

Davao del Sur State College

Brgy. Matti, Digos City

Dear Ma'am/Sir:

The undersigned is currently working on his/her thesis entitled, Sports Anxiety and Confidence Among College Athletes; The Mediating Effect of Friendship Quality."

In this regard, the researcher would like to request your approval to conduct the study in your area of responsibility. Rest assured that the confidentiality of the data collected will be an utmost priority. Attached herewith is the sample of the survey questionnaire that reflects the topics and questions to be discussed.

Looking forward to your favorable response on this request.
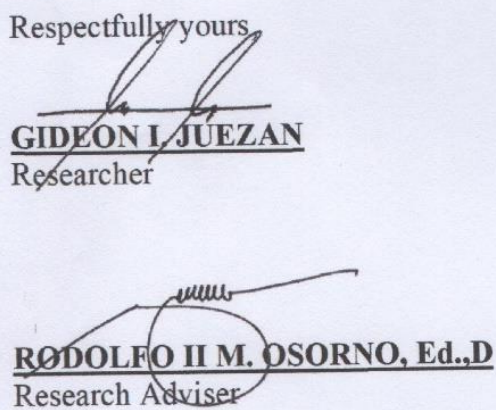

Noted by:

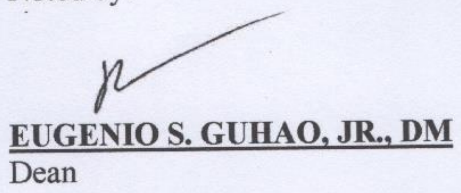

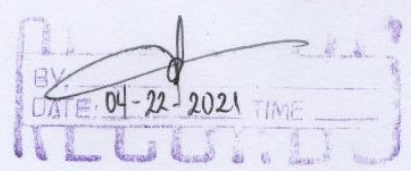

$$
\begin{aligned}
& \text { or trotu } \\
& \text { Nik at m }
\end{aligned}
$$

\section{AGTOP TRKE) :}

eppraver to cortDocat with

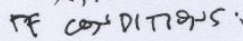

(1) OBsanvance is ikf princoufouldu.

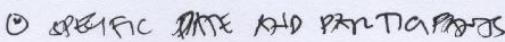

UST / PaTtus

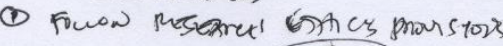


Gideon I. Juezan, Rodolfo II M. Osorno

SPORTS PERFORMANCE ANXIETY AND SPORTS CONFIDENCE AMONG

COLLEGE ATHLETES: THE MODERATING EFFECT OF FRIENDSHIP QUALITY

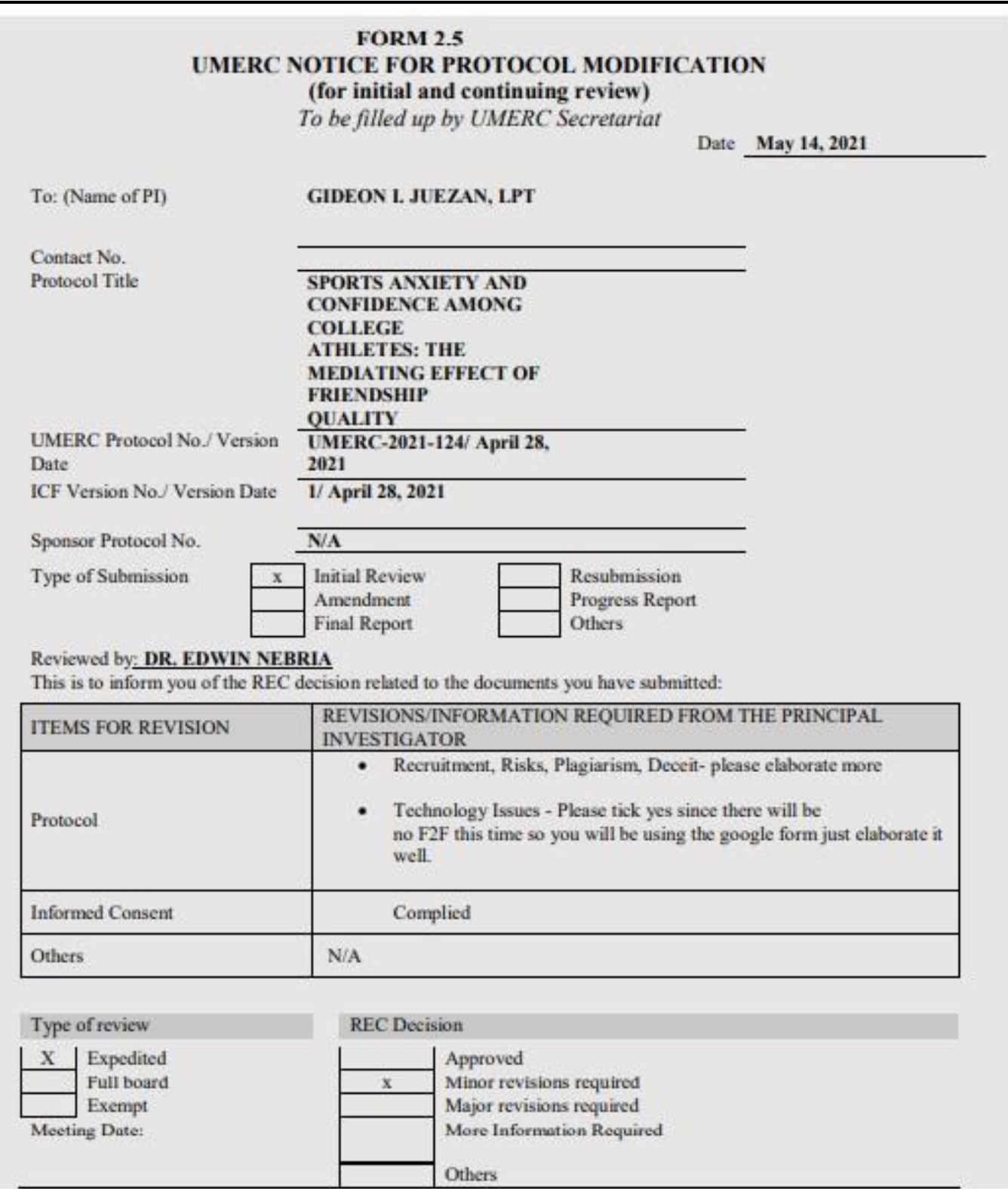



be applied to their work. Under the terms of this license, no permission is required from the author(s) or publisher for members of the community to copy, distribute, transmit or adapt the article content, providing a proper, prominent and unambiguous attribution to the authors in a manner that makes clear that the materials are being reused under permission of a Creative Commons License. Views, opinions and conclusions expressed in this research article are views, opinions and conclusions of the author(s). Open Access Publishing Group and European Journal of Physical Education and Sport Science shall not be responsible or answerable for any loss, damage or liability caused in relation to/arising out of conflict of interests, copyright violations and inappropriate or inaccurate use of any kind content related or integrated on the research work. All the published works are meeting the Open Access Publishing requirements and can be freely accessed, shared, modified, distributed and used in educational, commercial and non-commercial purposes under a Creative Commons attribution 4.0 International License (CC BY 4.0). 